\title{
Supply-Demand Analysis of Urban Emergency Shelters Based on Spatiotemporal Population Estimation
}

\author{
Xiaodong Zhang ${ }^{1} \cdot J^{1 a} \mathrm{Yu}^{1} \cdot$ Yun Chen $^{2} \cdot J^{2}$ iahong Wen ${ }^{1} \cdot$ Jiayan Chen $^{1} \cdot$ \\ Zhan'e Yin ${ }^{1}$
}

Published online: 25 June 2020

(C) The Author(s) 2020

\begin{abstract}
Supply-demand analysis is an important part of the planning of urban emergency shelters. Using Pudong New Area, Shanghai, China as an example, this study estimated daytime and nighttime population of the study area based on fine-scale land use data, census data, statistical yearbook information, and Tencent user-density big data. An exponential function-based, probability density estimation method was used to analyze the spatial supply of and demand for shelters under an earthquake scenario. The results show that even if all potential available shelters are considered, they still cannot satisfy the demand of the existing population for evacuation and sheltering, especially in the northern region of Pudong, under both the daytime and the nighttime scenarios. The proposed method can reveal the spatiotemporal imbalance between shelter supply and demand. We also conducted a preliminary location selection analysis of shelters based on the supplydemand analysis results. The location selection results demonstrate the advantage of the proposed method. It can be applied to identify the areas where the supply of shelters is seriously inadequate, and provide effective decision support for the planning of urban emergency shelters.
\end{abstract}

Keywords Big data China, population estimation - Probability density estimation - Supplydemand analysis · Urban emergency shelters

Jia Yu

yujiashnu@126.com

1 School of Environmental and Geographical Sciences, Shanghai Normal University, Shanghai 200234, China

2 CSIRO Land and Water, Canberra 2601, Australia

\section{Introduction}

It is estimated that $54 \%$ of the world's population resided in urban areas in 2014, and this percentage is projected to reach $66 \%$ by 2050 (UN 2014). As fast-growing and densely populated areas, cities are very sensitive and vulnerable to a variety of natural and human-made hazards (Blaikie et al. 2004; Dilley et al. 2005), such as earthquakes, floods, terrorist attachs, and chemical accidents. Urban emergency shelters are vital public places that can provide temporary space for residents when facing a disaster. Sound and effective planning of urban emergency shelters not only can strengthen the ability of governments to deal with disasters, but can also guarantee public security in cities (Johnson 2000). Existing studies on emergency shelter planning ( $\mathrm{Li}$ et al. 2012; Chen et al. 2013; Zhao et al. 2017) mainly focused on the evaluation and location selection of shelters by considering multiple factors: for example, traffic conditions, distances to shelters, population density, types of disasters, and capacity of shelters.

Various methods have been developed to evaluate the distribution of shelters. For instance, the Analytic Hierarchy Process (AHP) that is practical to multicriteria evaluation (Fan et al. 2011; Cheng and Yang 2012; Tong et al. 2012; Yu and Wen 2016), the weighted Voronoi diagram model (Tai et al. 2010; Dou et al. 2012) that considers the coverage of shelters, and the two-step floating catchment area algorithm (SFCA) model (Ye et al. 2008), all were proposed to evaluate the suitability of the existing emergency shelters. Location selection of shelters is also a significant task in urban emergency shelter planning. Sherali et al. (1991) proposed a restrictive condition model based on a nonlinear mixed-integer programming model to determine shelter locations. Other mathematical models 
were also applied to the location selection of shelters, for example, multi-objects models (Alçada-Almeida et al. 2009; $\mathrm{Xu}$ et al. 2018), bilevel-programming models (Kongsomsaksakul et al. 2005; Li et al. 2012; Xu et al. 2017), the max-covering model (Pan 2010), the SFCA model (Zhu et al. 2018), and the mathematical program with complementarity constraints model (Kulshrestha et al. 2011). Moreover, the AHP (Cheng and Yang 2011; Choi et al. 2012; Chu and Su 2012; Cetinkaya et al. 2016) and fuzzy method (Tsai et al. 2008; Trivedi and Singh 2017) were also used in location decision studies of emergency shelters.

Capacity of shelters and potential evacuation population are the two most important factors that have been considered in these studies. For instance, Kulshrestha et al. (2011) discussed demand uncertainty, which means the uncertainty of the number of evacuees using the emergency shelters during an evacuation, and adopted a robust optimization approach to address the demand uncertainty. Chu and $\mathrm{Su}$ (2012) calculated the per capita effective sheltering area as a significant evaluation indicator in the AHP analysis, which simply considers the relationship of capacity of shelter and evacuation population. Ye et al. (2008) took the parks in Shanghai Municipality, China, as emergency shelters and calculated the ratio of shelter capacity to residential population to estimate the accessibility of shelters. They also used inverse distance weighted (IDW) interpolation to estimate the accessibility of the whole study area. Zhu et al. (2018) calculated the supplydemand ratio by calculating the quotient of shelter population capacity and the sum of evacuee population. Yu and Wen (2016) also took the supply-demand ratio of each subdistrict in the Jing' an District, Shanghai as an important criterion in the AHP and carried out a weight sensitivity analysis of the evaluation for urban shelters. These studies considered evacuation population as "demand" and the capacity of shelters as "supply" to analyze the supplydemand relationship. However, these models only conducted the supply-demand analysis at the district or community scale, which did not discuss the supply-demand relationship from a microcosmic perspective and cannot reflect the satisfaction of a sheltering service at a fine spatial scale. Furthermore, spatiotemporal population change should be considered to cope with disaster threats (Freire et al. 2013), due to the activities and mobility of people, especially in urban areas (Aubrecht et al. 2012). Zhao et al. (2017) proposed an emergency shelter location model that minimizes the total setup cost of locating the shelters to satisfy time-varying shelter demand in a given urban area. However, the time-varying demand population estimation was only calculated at the community scale. Accurate population distribution estimation is significant to the supply-demand analysis for decision support in shelter planning.

In previous studies, many researchers conducted population distribution estimation by using various models, such as land use, population distribution, building volume, nightlight data, and agent-based models. The land use model is based on the linear relationship of land use and population, which depends on the high accuracy of land use classification (Choi et al. 2014; Lloyd and Nejad 2014; Shiode et al. 2014). These studies show that population distribution has a strong correlation with the land-use types. At nighttime, most people are in residential areas, while during the daytime, people are gathered in business areas, educational or medical facilities, and so on. Highresolution population distribution information can be extracted by combining the land use data with building data. The population distribution model estimates population distribution according to a distribution function, such as normal distribution (Sherratt 1960) and negative exponential distribution (Smeed 1964). However, the distribution function would be complex for big cities. The building volume model estimates population according to the relationship of population and building volume using, for example, Light Detection and Ranging (LIDAR)-based building volume data (Qiu et al. 2010; Lwin and Murayama 2011) and building footprint-based volume data (Yu and Wen 2016). The nightlight data model uses Defense Meteorological Program Operational Line-Scan System (DMSP/OLS) and National Polar-orbiting Partnership Visible Infrared Imaging Radiometer Suite (NPP/VIIRS) satellite products to estimate the population density distribution in the lighting areas (Yu et al. 2018). Although useful in some contexts, the method is not suitable for population estimation at a fine scale. Therefore, a population estimation method that combines land use with building volume data would be feasible and effective for supporting supply-demand analysis of shelters in this study.

Considering the time-dependence of population distribution, we propose a new supply-demand analysis method for urban emergency shelters. The main objective of this article is: (1) to investigate population estimation in the daytime and the nighttime at a fine scale that can provide the spatiotemporal population distribution data for further analysis ${ }^{1}$; and (2) to conduct the supply-demand analysis based on the spatial probability density estimation method. The advantage of the method presented in this study lies in two aspects: (1) the spatiotemporal supply-demand difference of emergency shelters can be revealed by

\footnotetext{
$\overline{1}$ In this study we consider 9:00-17:00 in work days as daytime and 0:00-4:00 as nighttime. In these time periods, population distributions are relatively stable.
} 
population estimation in the daytime and at night; and (2) the supply-demand analysis can be conducted from a microcosmic perspective, which makes the satisfaction evaluation for the capacity of the emergency shelters more accurate. In the following text: Sect. 2 introduces the study area; Sect. 3 presents the data used in this study; Sect. 4 proposes the methodology; Sect. 5 presents the results of supply-demand analysis and discussion; and in Sect. 6, we offer conclusions and an outlook to the future.

\section{Study Area}

Pudong New Area (Pudong) (Fig. 1) is a district in Shanghai Municipality, China, which is located to the east of the Huangpu River. It has 44 subdistricts, covering an area of $1210.41 \mathrm{~km}^{2}$. The northwestern part of Pudong is part of the central urban area of Shanghai, which is more developed in terms of the economy and society. Pudong is also one of the areas with the fastest population growth in China. With the rapid development of the area from 1990, a large number of people moved to Pudong mainly for business and other types of employment (Ding et al. 2003). In 1990, the population of Pudong was 1.38 million. The population rose to 2.40 million in 2000 and the growth rate was $73.1 \%$ in a decade. In 2009, Nanhui District was merged into Pudong District. At the end of 2015, 5.475 million permanent residents lived in Pudong (China 2016a). This great population growth may lead to increasing risks of population exposure to disasters or emergency events. A supply-demand analysis of urban emergency shelters in the area is critical to identify the areas where the need for disaster prevention cannot be satisfied. The supply-demand analysis results also can be used as a key criterion in generating optimal location selection decisions about new emergency shelters.

\section{Data}

We integrated multisource spatial data of the study area that mainly includes four different types as follows.

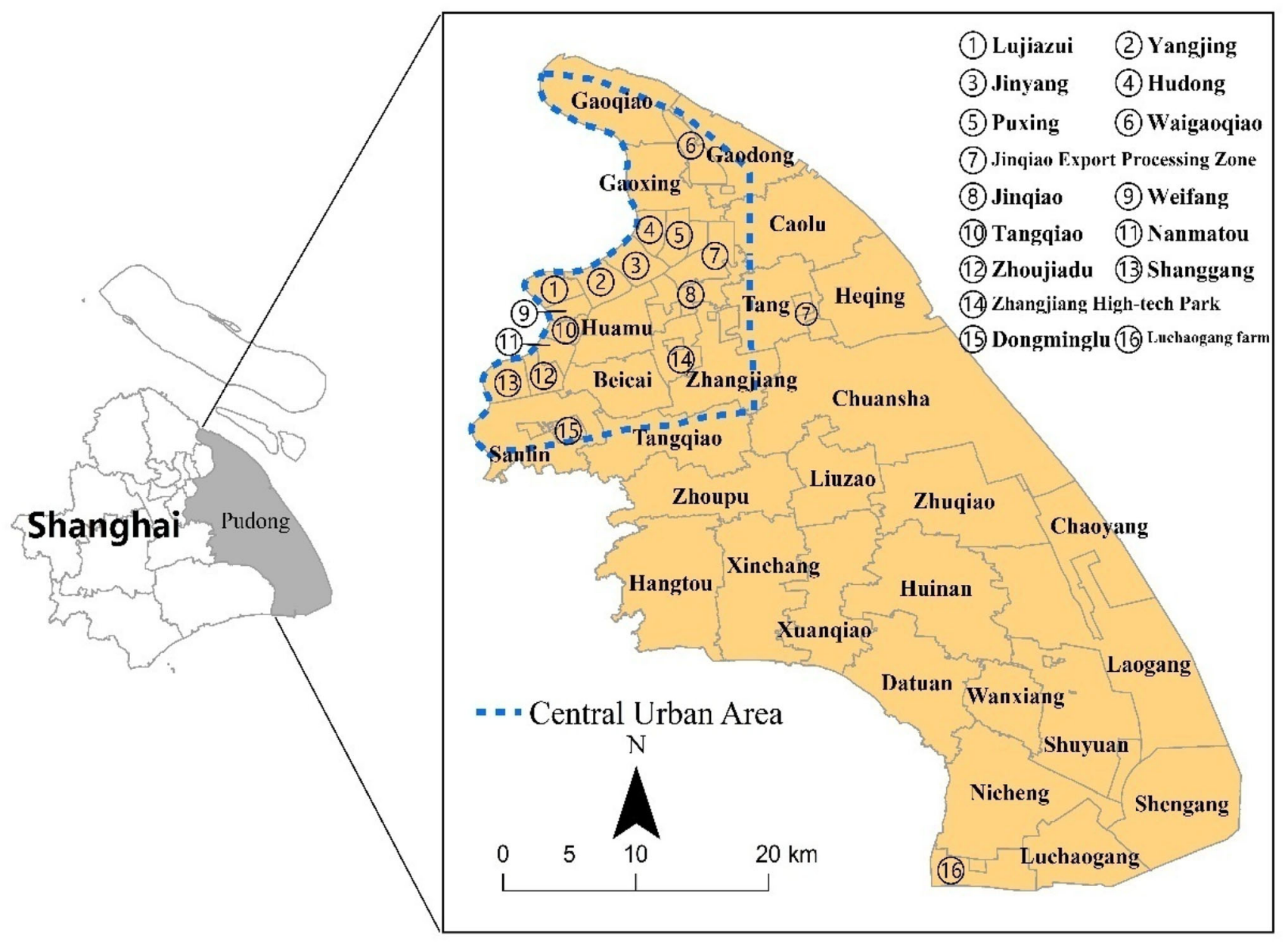

Fig. 1 Location of Pudong New Area within Shanghai Municipality, China 


\subsection{Land Use Data and Residential Building Data}

The land use data in 2015 were interpreted from highresolution remote sensing images $(0.5 \mathrm{~m}$ resolution) provided by the Google Map. By referring to the land use classification standard (NO. [2001]255) released by the Ministry of Land and Resources of China in 2002 (China 2002), we classified the land use of the study area into 12 land use types. We employed points of interest (POIs) data to refine the subdivision of parcels based on the classification information of POIs and reference to relevant studies (Long and Liu 2013). Figure 2 shows the land use of Pudong in 2015. The land use distribution shows that residential lands are mainly located in the northwestern area of Pudong (central urban area). Agricultural lands are distributed outside the central urban area (in the suburbs) of Pudong.

The footprints of the residential buildings were also interpreted based on the high-resolution remote sensing images in 2015. In the study area, more than 62,000 residential buildings were interpreted, of which $55.4 \%$ were 0-6 story buildings, $19.2 \%$ were $7-12$ story buildings, $21.6 \%$ were $13-24$ story buildings, and $3.8 \%$ were buildings that have more than 25 floors. Meanwhile, the number of floor levels of each residential building was also assigned to conduct the estimation of population in a fine spatial scale, which are introduced in the subsequent sections.

\subsection{Population Data}

The population data were obtained from the Sixth National Census of Shanghai in 2010 (China 2011a) and the Bulletins of the Third Economic Census of Pudong (China 2015a). The data obtained from the population census include residential population in different ages of each residential committee in the study area. The data obtained from the economic census include the total working population of each subdistrict. In this study, we estimated the population distribution in 2017. Because the residential population data are from 2010, the residential population change was estimated based on the natural population growth rate from 2010 to 2017 . The detailed estimation method will be introduced in Sect. 4.1.

\subsection{Tencent User Density Data}

Tencent user density (TUD) big data is another important data source that was used to estimate population distribution in the study areas. The TUD, which is released by Tencent ${ }^{2}$ hourly, reflects the density of the users who were

\footnotetext{
${ }^{2}$ http://www.qq.com.
}

using Tencent applications such as QQ, WeChat, and Tencent Map that provide Tencent Location Based Service (LBS) for users. According to recent reports, ${ }^{3}$ Tencent users account for more than $70 \%$ of the total population in China. This number is more than $90 \%$ in China's first-tier cities, that is, Beijing, Shanghai, Guangzhou, and Shenzhen. The Tencent LBS receives more than 50 billion requests every day and the huge amounts of requests ensure the reliability of the data. Tencent records the locations of users and processes the number of users in each pixel unit into density weights, which result in a real-time density measure. The value of the density weight in a location has a positive correlation with the number of Tencent LBS users in this location at a certain time. The TUD is shown as a population heat map at a spatial resolution of $25 \mathrm{~m}$.

The TUD has been proved to be effective to reflect the spatiotemporal population distribution accurately and has been applied in many recent studies. Yao et al. (2017) estimated urban population distribution by integrating multisource geospatial big data including TUD, and claimed that the method had the best accuracy (Pearson $\mathrm{R}=0.8615, \mathrm{p}<0.0001)$ compared with the results of previous population mapping methods. Chen et al. (2017) proposed a novel method for delineating urban functional areas based on TUD and building data, and applied a dynamic time warping distance based k-medoids method to group buildings with similar social media activities into functional areas; Niu et al. (2017) integrated multisource big data, including TUD data, to infer the functions of urban buildings and the overall detection rate was $72.22 \%$; Chen, Liu et al. (2018a) used TUD to analyze the spatiotemporal distribution of urban park users, and the method proved to be suitable for measuring urban green space use at a city-level or even larger scale.

Based on the above studies, the TUD big data are suitable to be used in the research field of population activity distribution. We used TUD to conduct supplementary estimation of population distribution in the areas where the detailed census data are not available, which mainly includes the daytime working population distribution in business and industrial areas. To obtain the TUD data, we developed a web crawler to fetch the TUD big data of the study area from the "Easygo" website. ${ }^{4}$ For this study, we accessed the TUD in the afternoon (about 3 p.m.) on weekdays from January to April 2018, which can represent the daytime population distribution well in the study area.

\footnotetext{
${ }^{3}$ http://www.bigdata.qq.com.

${ }^{4}$ http://c.easygo.qq.com/eg_toc/map.html.
} 
Fig. 2 Land use of Pudong New Area, Shanghai Municipality, China (interpreted by the faculty members and students in the School of Environmental and Geographical Sciences, Shanghai Normal University)

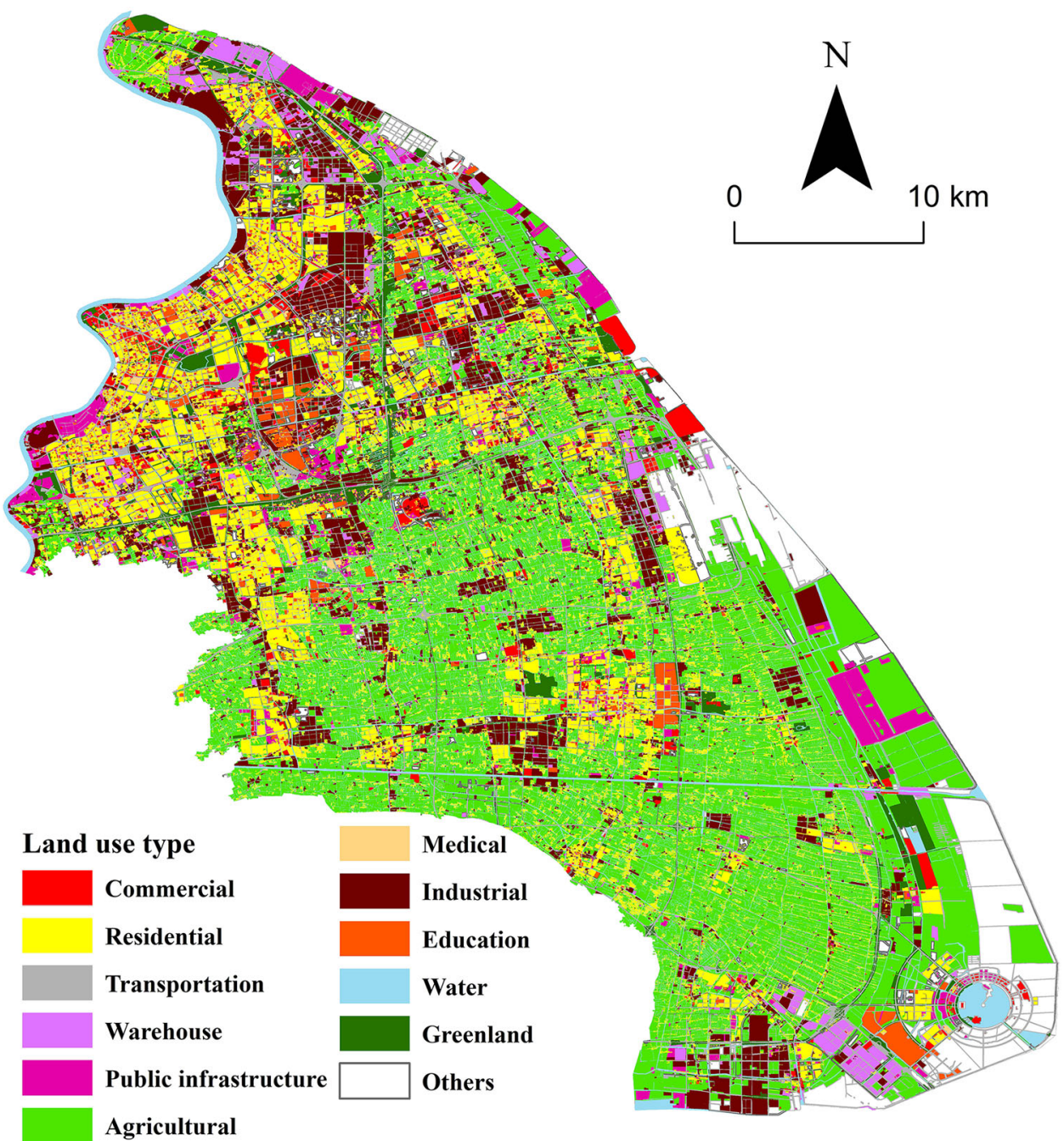

\subsection{Shelter Data}

The planning of emergency shelters in the central area of Shanghai was published by the local government in 2008 . Although many emergency shelters have been planned and constructed in Shanghai in many years, they still cannot satisfy the demand of disaster prevention and emergency management because of the imbalance of the distribution and capacities of urban shelters and the spatial sheltering demand (Dai et al. 2013). At the end of 2017, there was only one large emergency shelter in Pudong. Therefore, we selected all potentially available shelters as assumed shelter locations according to the land use types and the Design Standard for Emergency Shelter (DG/TJ 08-2188-2015), which was released by the government of Shanghai (China 2016b). In this design standard, there are three classes of emergency shelters (Table 1).

Based on the practice in Shanghai, choosing large public spaces, such as green areas and parks, as shelters can better help to cope with natural or human-made hazards and disasters (Zhao et al. 2013). To avoid flood hazards, the emergency shelters should be located at least $500 \mathrm{~m}$ away from the shore (Jin 2013). We conducted the potential shelter selection work under the scenario of an earthquake disaster according to the design standard (DG/TJ 08-21882015) and other criteria for Shanghai from previous studies.

Referring to the Class I standard in Table 1, we selected 77 green areas, parks, and stadiums whose areas are over $20,000 \mathrm{~m}^{2}$ and these assumed (potential) shelters can cover the population within the distance of $5 \mathrm{~km}$. As to the emergency shelters that are of Class II standard, we chose 55 green areas, parks, and stadiums whose areas are between $4000 \mathrm{~m}^{2}$ and $20,000 \mathrm{~m}^{2}$. These assumed shelters can cover the population within the distance of $1 \mathrm{~km}$. Moreover, 540 sports grounds in schools were selected as assumed shelters of Class III standard and they can cover the population within the distance of $0.5 \mathrm{~km}$.

The population capacity of a shelter can be calculated by the area of the shelter divided by the "effective area per 
capita" of its class (Table 1). All the shelter location information was collected from the land use data and verified by Gaode ${ }^{5}$ POIs. The distributions of the assumed shelters are shown in Fig. 3.

\section{Methodology}

The supply-demand analysis framework of urban emergency shelters is presented in Fig. 4, which calculates and spatially expresses the difference between the demand of the evacuation population and spatial supply of shelters. In this procedure, we first estimate daytime and nighttime population in a fine scale, respectively. To analyze the spatial supply of shelters from a microcosmic perspective, an exponential function-based probability density estimation method is used to reflect the spatial heterogeneity of the supply to nearby areas. Supply-demand analysis is conducted and the results are presented in maps to facilitate further location selection. Finally, a preliminary location selection analysis of shelters is conducted based on the supply-demand analysis results to support the planning of emergency shelters in the future (Table 2).

\subsection{Nighttime Population Distribution Estimation}

At nighttime, people are in residential buildings in high probability. Therefore, we assume that the urban residents are all distributed in residential buildings and the floating population is not considered in this study because of its random distribution and small population size. Based on this assumption, the nighttime population can be estimated by using the volumetric method (Eqs. 1, 2, and 3) as follows:

$$
\begin{aligned}
& V_{B(k)}=A_{B(k)} \cdot F_{B(k)} \cdot H \\
& P_{B(n)}=P_{C(m)} \cdot V_{B(n)} /\left(\sum_{k=1}^{K} V_{B(k)}\right) \\
& P_{\text {nighttime }}=\sum_{m=1}^{M} P_{c(m)}=\sum_{n=1}^{N} P_{B(n)}
\end{aligned}
$$

where the $V_{B(k)}$ is the volume of the $k$-th residential building; $P_{B(n)}$ is the population of the $n$-th residential building; $P_{\text {nighttime }}$ is the total population at night in the study area; $\mathrm{A}_{B(k)}$ is the footprint area of the $k$-th building; $F_{B(k)}$ is the number of floors of the $k$-th building; $H$ is the height of each floor of the buildings (we consider $H$ as a constant for all the residential buildings); $P_{c(m)}$ is the population of the $m$-th community in which the building is located; $K$ is the total number of residential buildings in the

\footnotetext{
$\overline{5}$ Gaode is a map service company in China.
}

$m$-th community; $M$ is the total number of communities; $N$ is the total number of residential buildings in the study area.

The community population was acquired from the Sixth National Census of Shanghai, carried out in 2010 (China 2011a). To map the population distribution in 2017, population change needs to be considered to extrapolate the population data from 2010 to 2017 . The natural population growth rate method is considered as one of the main population prediction methods that has been adopted in current land-use planning in China (Tang and Zhao 2005). Using this method, we calculated the natural population growth rate of each community from the Shanghai Pudong New Area Statistical Yearbook of 2011 and of 2017 (China $2017,2011 b)$ and derived the community population in 2017.

\subsection{Daytime Population Distribution Estimation}

The daytime population has obvious differences in spatial distribution when compared with the nighttime population. People are distributed in different areas in the daytime instead of staying in residential buildings. Therefore, the daytime estimation work is more complicated than that at nighttime. Previous studies mainly divided the daytime population into several types and built population-land usetime models according to the relationship between different land use types and population types in daytime and nighttime (Qi et al. 2015). Referring to these previous studies, this study divided the daytime population into three types: (1) stay-at-home population, which represents the people who are at home in the daytime, and mainly includes the elderly and preschool children; (2) working population, which are the people who go to nonresidential workplaces regularly in the daytime, such as office staffs, industrial workers, and so on; (3) students; and (4) other populations, including tourists and hospital inpatients, and so on. This study used Eq. 4 to conduct the estimation of daytime population.

$P_{\text {daytime }}=\sum_{n=1}^{N} P_{B d(n)}+\sum_{m=1}^{M} P_{W(m)}+\sum_{l=1}^{L} P_{S(l)}+\sum_{k=1}^{K} P_{O(k)}$

where $P_{\text {daytime }}$ is the population in the daytime, $P_{B d(n)}$ is the daytime population of the $n$-th residential building, $P_{W(m)}$ is the daytime population of the $m$-th commercial land. $P_{S(l)}$ is the daytime population of the $k$-th educational land. $P_{O(k)}$ is the daytime population of the $k$-th medical land.

Residential population in the daytime mainly includes the elderly and preschool children and these data can be obtained from the census. The population aged under 4 or above 60 is filtered and their data can be processed by the 
Table 1 Classes of emergency shelters in Shanghai based on the Design Standard for Emergency Shelter (DG/TJ 08-2188-2015)

\begin{tabular}{lllll}
\hline Class & Population $(1000$ persons $)$ & Capacity for continued opening per event (day) & Effective area per capita $\left(\mathrm{m}^{2}\right)$ & Service radius $(\mathrm{m})$ \\
\hline Class I & $>5$ & $>30$ & $>3.0$ & 5000 \\
Class II & $1-5$ & $10-30$ & $>2.0$ & 1000 \\
Class III & $<1$ & $<10$ & $>1.5$ & 500 \\
\hline
\end{tabular}

Source China (2016b)
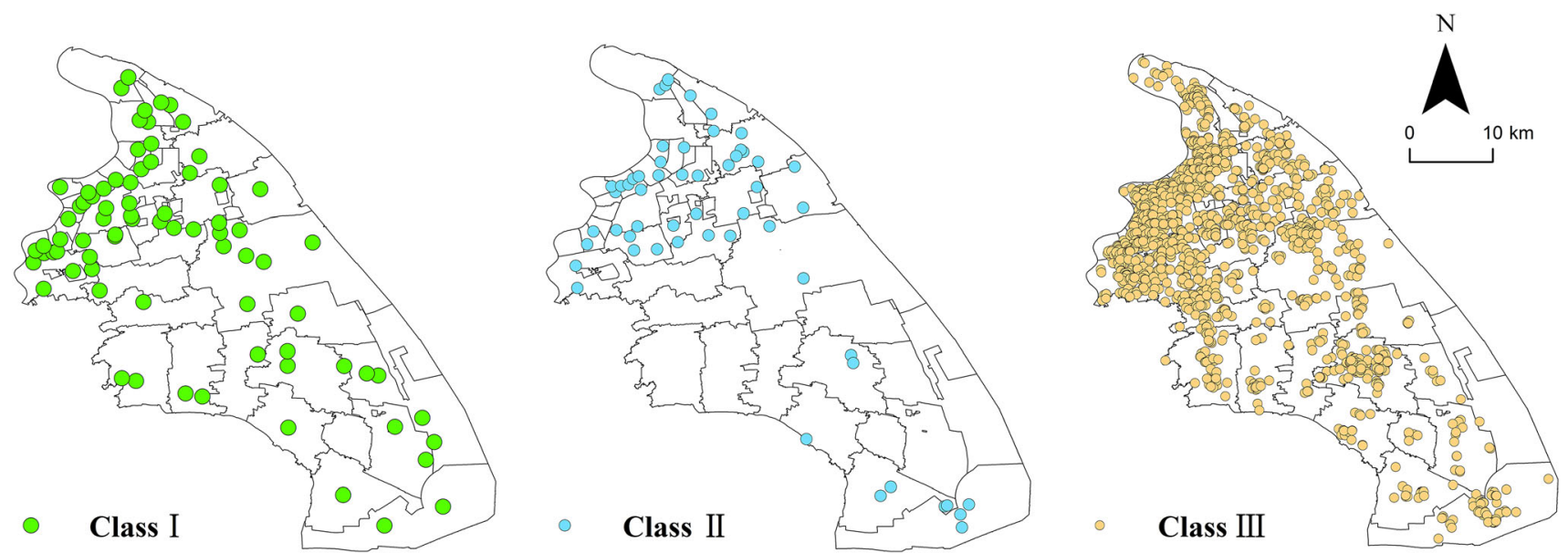

Fig. 3 Distribution of assumed (potential) shelters in Pudong New Area, Shanghai Municipality, China

method similar to that for the nighttime residential population. $P_{B d(n)}$ in Eq. 4 can be estimated by Eq. 5:

$P_{B d(n)}=P_{C d(m)} \cdot V_{B(n)} /\left(\sum_{k=1}^{K} V_{B(k)}\right)$

where $P_{C d(m)}$ is the elderly and preschool children in the $m$ th community; $V_{B(n)}$ is the volume of the $n$-th residential building, $K$ is the total number of residential buildings in the $m$-th community.

The method used to estimate the working population has some departures from those employed in previous studies. These studies (Qi et al. 2015; Yu and Wen 2016) have the following limitations: (1) The working population estimates were outdated because of the limitation of the data availability of enterprises and factories; and (2) It is difficult to estimate the spatial distribution of the working population in fine scale. Considering these limitations, TUD big data are applied to calculate the population weights of commercial and industrial land, respectively, which can help to calculate the population of the commercial and industrial areas. $P_{W(m)}$ in Eq. 4 can be estimated by Eqs. 6 and 7:

$P_{W(m)}=P_{S d(i)} \cdot w_{(i, j)}$ $w_{i, j}=T U D_{(i, j)} / \sum_{j=1}^{J} T U D_{(i, j)}$

where $P_{S d(i)}$ is the working population of the $i$-th subdistrict. $w_{(i, j)}$ is the population weight of the $j$-th commercial land or industrial land in the $i$-th subdistrict. $T U D_{(i, j)}$ is the TUD of the $j$-th commercial land or industrial land in the $i$ th subdistrict. The working population of each subdistrict is acquired from the Bulletins of the Third Economic Census of Pudong, Shanghai (China 2015a). Population in educational lands or hospitals is calculated by the data from the Shanghai Pudong New Area Statistical Yearbook (China 2017).

To assess the accuracy of the working population estimation method, we collected official survey data of the working population while visiting the subdistrict offices and residential committee offices. We used the Pearson correlation coefficient and a coefficient of determination $\left(\mathrm{R}^{2}\right)$ to compare the predicted working population with the statistical working population collected from the subdistrict governments in the field investigations.

\subsection{Spatial Supply of Urban Emergency Shelters}

As mentioned in the Introduction section, the supply-demand analysis of previous studies was limited at the 
Fig. 4 Supply-demand analysis framework to match potential evacuation population with the available supply of urban emergency shelters

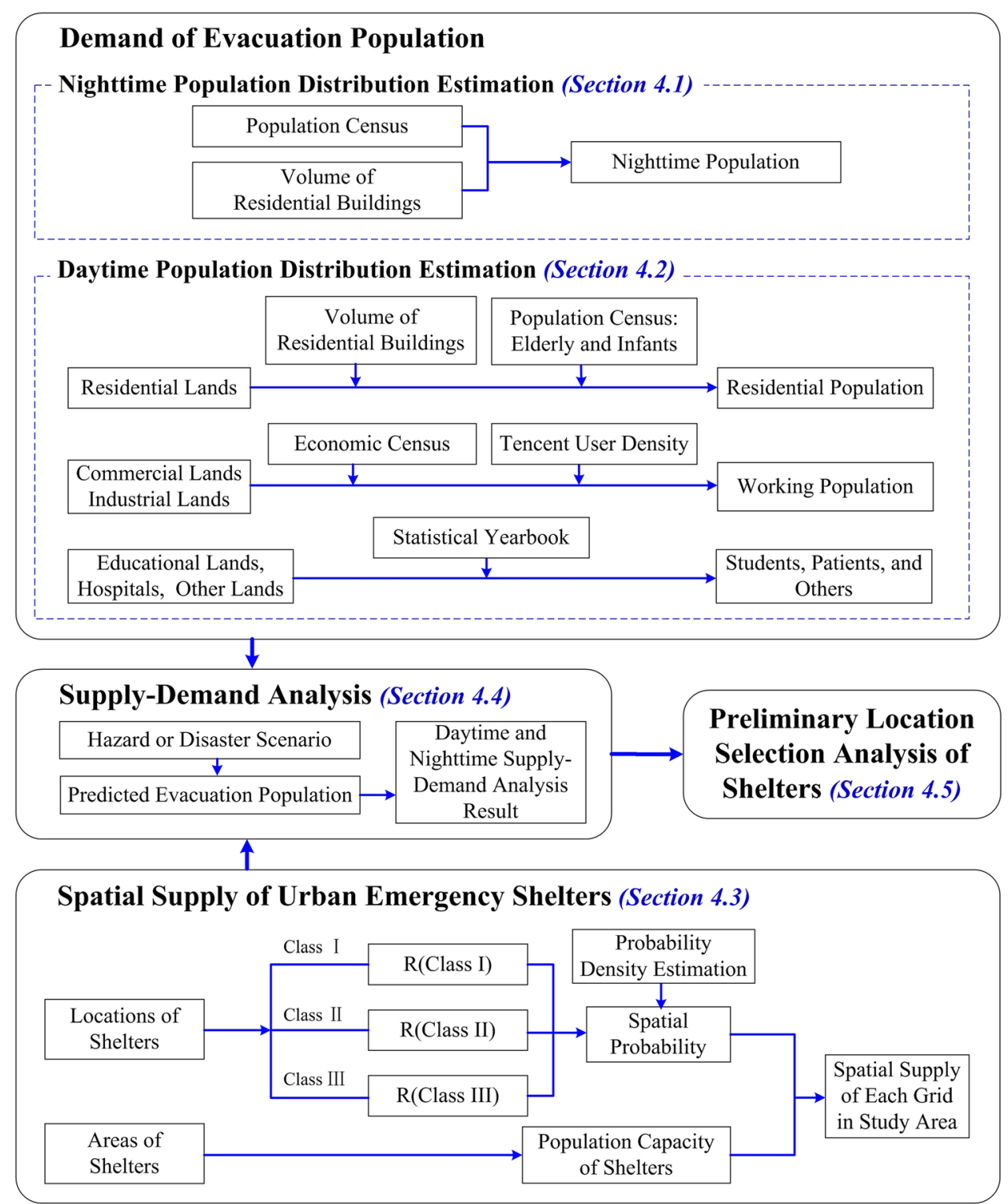

regional or community scale. Therefore the ratio of supplydemand cannot be described from a microcosmic perspective. Considering this limitation, we developed a new method based on spatial probability density estimation to calculate the spatial supply at a fine scale. The method can be divided into the following steps:

(1) Determine the spatial probability distribution of supply of each shelter within its service area; and

(2) Calculate the spatial supply of a location obtained from an emergency shelter. The value of the spatial supply can be estimated by Eq. 8:

$S S=\sum_{s=1}^{S} p_{s} \cdot P C_{s}$ where $S S$ is the spatial supply of a location from the nearby emergency shelters; $P C_{s}$ is the population capacity of the $s$ th shelter; $p_{s}$ is the probability density of a grid in the spatial probability distribution of the $s$-th shelter. In the equation, the value of $S S$ is sensitive to the estimation of $p_{s}$.

We assumed the scenario of an earthquake disaster in this study. Given the characteristics of earthquake disasters that may be quite different from other hazards or disasters, when an earthquake occurs, it is very urgent for a large number of people to be evacuated to emergency shelters. Considering the timeliness of sheltering, the spatial supply of an emergency shelter is relative to the distance to the shelter. Therefore, we set the distance to shelter as an independent variable $r$. The $p_{s}$ and $r$ have the relationship that $p_{s}$ decreases while the value of $r$ increases. In previous 
Table 2 Nomenclatures used in Sect. 4

\begin{tabular}{|c|c|}
\hline Nomenclature & Meaning \\
\hline$P_{\text {nighttime }}$ & the total population at nighttime in the study area \\
\hline$V_{B(k)}$ & the $k$-th residential building \\
\hline$P_{B(n)}$ & the population of the $n$-th residential building \\
\hline $\mathrm{A}_{B(k)}$ & the footprint area of the $k$-th building \\
\hline$F_{B(k)}$ & the number of floors of the $k$-th building \\
\hline$P_{c(m)}$ & the population of the $m$-th community \\
\hline$P_{\text {daytime }}$ & the total population in the daytime in the study area \\
\hline$P_{B d(n)}$ & the daytime population of the $n$-th residential building \\
\hline$P_{W(m)}$ & the daytime population of the $m$-th commercial land \\
\hline$P_{S(l)}$ & the daytime population of the $k$-th educational land \\
\hline$P_{C d(m)}$ & the elderly and preschool children in the $m$-th community \\
\hline$P_{S d(i)}$ & the working population of the $i$-th subdistrict \\
\hline$w_{(i, j)}$ & the population weight of the $j$-th commercial land or industrial land in the $i$-th subdistrict; $w_{(i, j)}$ is between 0 and 1 . \\
\hline$T U D_{(i, j)}$ & the Tencent user density (TUD) of the $j$-th commercial land or industrial land in the $i$-th subdistrict \\
\hline$S S$ & the spatial supply from the surrounding emergency shelters for a location \\
\hline $\mathrm{PC}_{\mathrm{s}}$ & the population capacity of the $s$-th shelter \\
\hline$p_{s}$ & the probability density of a grid in the spatial probability distribution of the $s$-th shelter \\
\hline
\end{tabular}

studies of human mobility, it was proved that human spatial travel behaviors are in power-law distribution or negative exponential distribution at both population and individual levels (Brockmann et al. 2006; Gonzalez et al. 2008; Jiang et al. 2009; Song et al. 2010). Chen, Qiao et al. (2018b) demonstrated that human spatial travels were in a negative exponential distribution in Beijing, China, by using 3 months' GPS data on taxis. Song et al. (2017) also demonstrated a similar distribution in Shanghai, by using two-week mobile phone data. The $p_{s}$ and exponential function can be calculated by Eqs. 9, 10, and 11:

$p_{s}=\mathrm{p}(r)=\mathrm{ae}^{-\mathrm{b} r}, r \in[0,+\infty)$

$\mathrm{p}(\mathrm{wa})=\int_{0}^{+\infty} \mathrm{ae}^{-\mathrm{b} r}(2 \pi r) \mathrm{d} r=1$

$\mathrm{E}(r)=\int_{0}^{+\infty} \mathrm{ae}^{-\mathrm{b} r}\left(2 \pi r^{2}\right) \mathrm{d} r$

where $r$ is the Euclidean distance from a location to the shelter; $\mathrm{p}(r)$ is the probability of $S S$ for a location whose travel distance to the shelter is $r$; $\mathrm{p}$ (wa) is the integration of $\mathrm{p}(r)$ in the whole area (three-dimensional space), whose value is $1 ; \mathrm{E}(r)$ is the mathematical expectation of $r$; a and $\mathrm{b}$ are constants.

Song et al. (2017) calculated the negative exponential function of human spatial travel behaviors of Shanghai. In their study, the values of $a$ and $b$ were calculated by making the value of $E(r)$ equal to the average population trip distance of Shanghai. The values of $a$ and $b$ are
0.000276 and 0.0417 . We assumed that the probability of $S S$ should be similar to the probability distribution of the actual population travel distances, which can make SS more in accordance with the actual situation. Therefore, we use the negative exponential function of human spatial travel behaviors of Shanghai to estimate the spatial probability density of $S S$ in this study.

The spatial supply of a grid can be calculated by accumulating the spatial supplies of the nearby shelters (these shelters may be of different classes). The spatial supply of the grid can be calculated in Eqs. 12 and 13:

$$
\begin{aligned}
& S S_{m, i, c}=P C_{i} \cdot \int_{r-g s / 2}^{r+g s / 2} p(r, i) \cdot g s d r / \int_{0}^{R(c)} p(r) \cdot(2 \pi r) d r \\
& S S_{m}=\sum_{i=1}^{I} S S_{m, i, c}, c \in\{\text { Class I, Class II, Class III }\}
\end{aligned}
$$

where $S S_{m, i, c}$ is the spatial supply of the $m$-th grid obtained from the $i$-th nearby shelter (the shelter is of $c$ type); $S S_{m}$ is the total spatial supply of the $m$-th grid acquired from the nearby shelters; $r$ is the distance from a location to the shelter and the location is in the center of a grid; $g s$ is the grid size of the spatial grid data of the study area; $P C_{i}$ is the population capacity of the $i$-th shelter; $p(r, i)$ is the probability density of a location whose distance to the $i$-th shelter is $r ; I$ is the total number of shelters from which the grid can acquire spatial supply; $\mathrm{R}(c)$ is the service distance of the $c$ type shelter. In this study, R (Class I) $=5000 \mathrm{~m}, \mathrm{R}$ $($ Class II $)=1000 \mathrm{~m}$, and R $($ Class III $)=500 \mathrm{~m}$. 


\subsection{Supply-Demand Analysis}

The supply-demand analysis mainly calculates the differences of spatial supply and demand of sheltering service both in the daytime and at nighttime. Many factors affect the demand for sheltering, such as regional population, the intensity of a hazard, and residents' willingness to be evacuated. Especially, the number of evacuees greatly depends on the type and intensity of a hazard or disaster. To predict the evacuation population and estimate the sheltering demand under an earthquake scenario, we took the study of Chen et al. (2016) as a starting point. These authors summarized the estimation method of the population loss rate in buildings of different architectural structures and in different areas in China from the previous study of Yin and Yang (2004) and simplified in a table the relationship between the evacuation ratio of different land uses and seismic intensity. Examination of this table reveals the evacuation rates of different land uses in this study area (Table 3). For example, when an earthquake of intensity 9 occurs, the population evacuation ratios in urban and rural residential land are $38.39 \%$ and $63.56 \%$, respectively. Multiplying the population estimation results of different land uses with the relative evacuation ratios, the predicted evacuation population, or the demand of sheltering, can be generated. After comparing this predicted evacuation population and the spatial supply of shelters, the spatiotemporal heterogeneities of supply-demand of emergency shelters are mapped. The mapping results of daytime and nighttime can be compared to find the difference and changing trend of the supply-demand from nighttime to daytime.

\subsection{Preliminary Location Selection Analysis of Shelters Based on Supply-Demand Analysis}

To demonstrate the feasibility and advantage of the daytime and nighttime supply-demand analysis results of

Table 3 Population evacuation ratios under different seismic intensities in Shanghai Municipality, China

\begin{tabular}{lll}
\hline Land use type & $\begin{array}{l}\text { Seismic } \\
\text { intensity }\end{array}$ & $\begin{array}{l}\text { Population } \\
\text { evacuation ratio } \\
(\%)\end{array}$ \\
\hline Urban residential land, commercial & 9 & 38.39 \\
land, transportation land, & 8 & 21.71 \\
warehouse, medical land, & 7 & 10.52 \\
industrial land, educational land & 9 & 63.56 \\
Rural residential land & 9 & 58.57 \\
& 8 & 41.29 \\
\hline
\end{tabular}

Source Chen et al. (2016) shelters, our study conducted a preliminary location selection analysis on the basis of these results.

In previous studies, evaluation of location selection suitability by AHP is a commonly used method to solve shelter location selection problems ( $\mathrm{Yu}$ and Wen 2016). Meanwhile, max-covering of the evacuation population is an important factor that has been widely considered in shelter location selection studies (Pan 2010). With reference to previous studies, we conducted the preliminary location selection steps as follows: (1) calculate the unsatisfied daytime and nighttime population spatially and integrate them by overlay calculation; (2) evaluate the location selection suitability for emergency shelters with consideration of multiple factors using the AHP method; (3) find the locations that can maximally cover the surrounding unsatisfied population in the suitable areas of shelter location selection using the focal statistics method, which can calculate a statistic on a raster over a specified neighborhood (ESRI 2017). First, the grids in the suitable areas were all selected as alternative locations. Second, if the sum area of unavailable lands (residential, commercial, medical, warehouse, and transportation areas) in a grid is above $50 \%$ of the total area of the grid, or the available lands are scattered, the grid was removed from the alternative locations because this location cannot provide sufficient space for building a shelter. In the third step, the focal sum statistics method was used to calculate the covered surrounding unsatisfied population for each alternative location. In the final procedure, the focal maximum statistics method was used to find the locations that can maximally cover the surrounding unsatisfied population in the searching regions. These locations are the shelter location selection results.

\section{Results and Discussion}

Analyzing the spatial supply and demand of urban emergency shelters in Pudong on the basis of the proposed method, the results were generated as follows.

\subsection{Population Estimation Results}

Using the population estimation method, it was estimated that the daytime population in the study area is about 3.4 million, which rises to 5.7 million at night. The gap between the total daytime population and nighttime population indicates the separation between the employment and residential locations of the residents. Many people leave their living place in the study area and work in other districts in the daytime. Compared with the statistical working population, the estimated working population in this study shows good accuracy (Pearson $\mathrm{R}=0.78$, 
$\mathrm{R}^{2}=0.615, \quad \mathrm{p}<0.0001, \quad \mathrm{RMSE}=1198.326, \quad \mathrm{MAE}=$ 908.9479). The accuracy evaluation method was from Yao et al. (2017). The results demonstrate the accuracy of the TUD data and the good performance of the proposed estimation method of daytime working population.

Figure 5 presents the daytime and nighttime population distribution in the study area. It can be seen that both in the daytime and at night, people gathered in the central urban area (Fig. 1). In the daytime, three subdistricts of PudongChuansha, Heqing, and Huinan (Fig. 1)—also gathered a large population.

When the daytime population distribution is compared with the nighttime distribution (Fig. 6), it shows that in the daytime many people gathered in the northern region of Pudong, including Lujiazui Financial and Trade Zone, Zhangjiang Hi-Tech Park, and Waigaoqiao Free Trade Zone (Fig. 1). These subdistricts have large, densely-built commercial areas and attract many commuters from the working population. However, population density greatly decreases in these areas at night. For example, there is only about one-third of the population at nighttime in Lujiazui when compared with this subdistrict's daytime population. At nighttime, there is a large residential population in the north of Pudong such as Yangjing, Jingyang, Sanlin, and
Puxing subdistricts (Fig. 1). The population also significantly decreased in the daytime in these subdistricts. For example, daytime population in Sanlin subdistrict is less than one-third of population in the nighttime.

The spatial analysis results indicate that Pudong is a typical district with a job-housing separation situation, which means that many people who live in Pudong work in other districts. This characteristic is related to the nature of urban land-use planning in Shanghai. Many commercial centers are located in the central area of Shanghai, which is in west Pudong. The housing prices in the central area are very high. Large areas of Pudong are urban expansion regions, and the housing prices are much lower. Therefore, Pudong attracts a large residential population to live in it, and the nighttime population is obviously bigger than the daytime population.

\subsection{Supply-Demand Analysis Results}

The supply-demand analysis in this study considers the spatial supply of emergency shelters and the demand for sheltering. The sheltering demand is greatly influenced by the type and intensity of a potential hazard. Pudong New Area is an industrial agglomeration district and has a large

\section{(a) Daytime population}

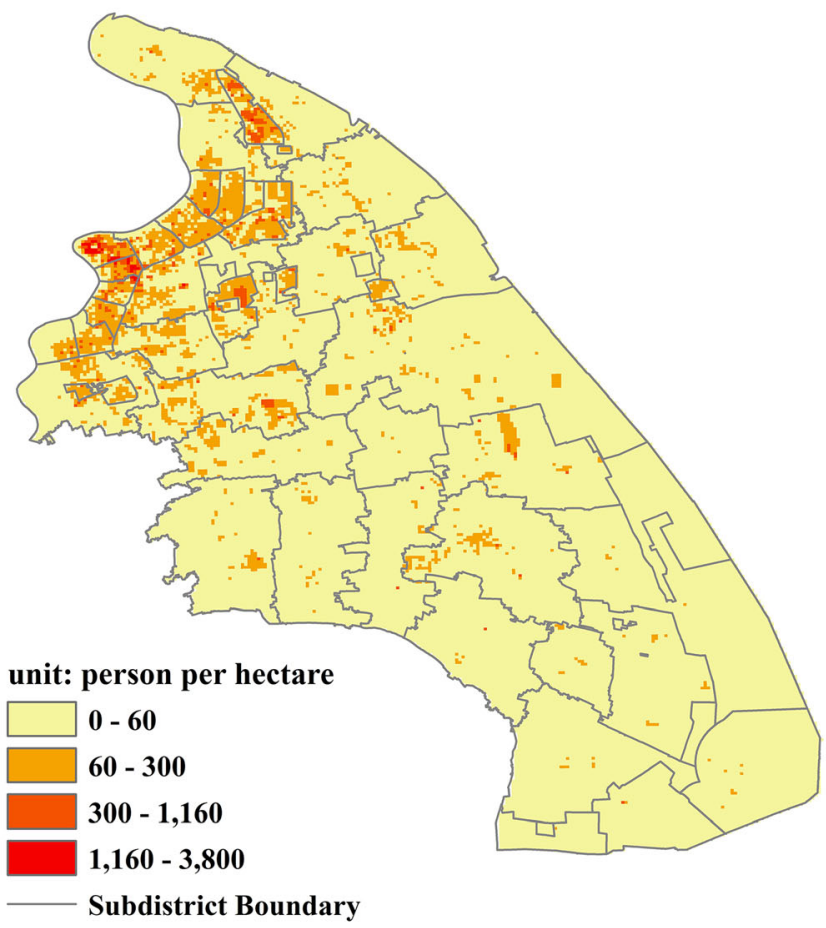

\section{(b) Nighttime population}

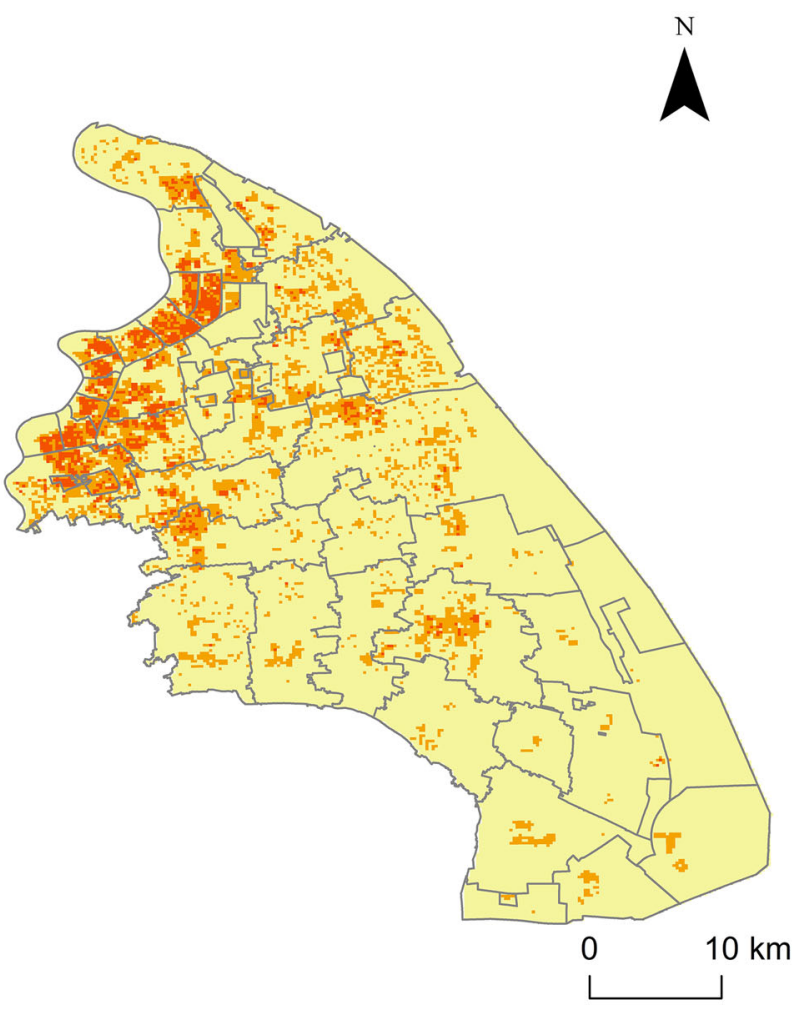

Fig. 5 Daytime (a) and nighttime population estimation results (b) in Pudong New Area, Shanghai, China (100 m resolution) 
(a)

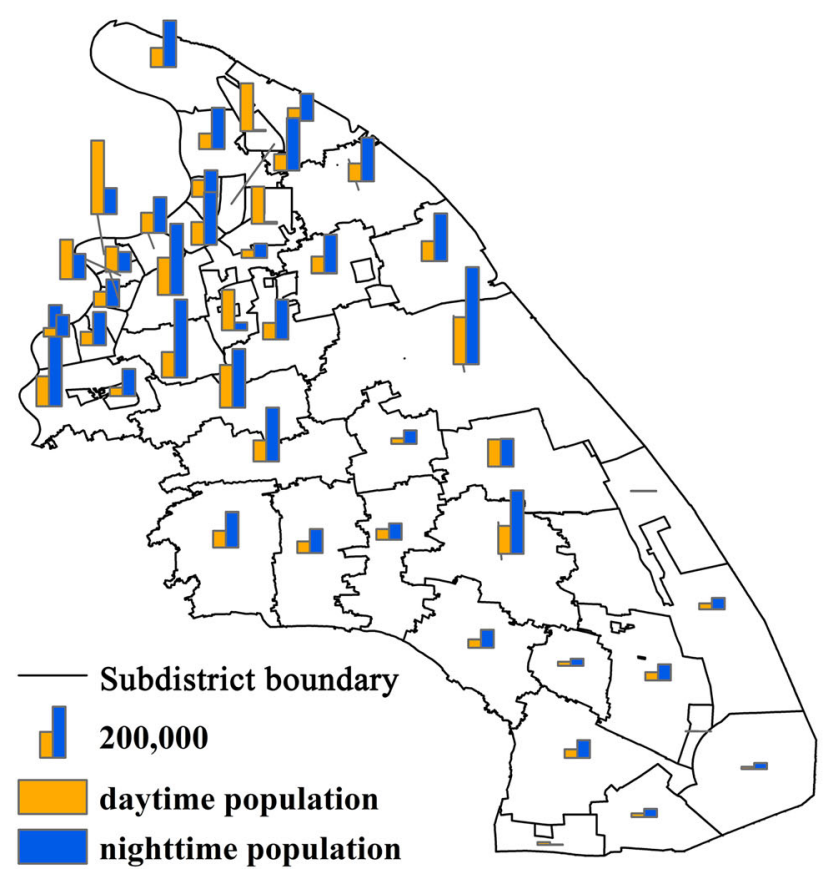

Fig. 6 Comparison of daytime and nighttime population distribution in Pudong New Area, China. a Comparison at the subdistrict scale; b Population difference between daytime and nighttime at the fine

population. If a catastrophe happens, it will lead to serious consequences because of this high population and economic exposure. In this study, an earthquake that has the intensity of 9 was assumed as the disaster scenario. Although intensity 9 might be high for this area, according to the historical records and the latest zoning map (China 2015b), it is essential to consider extreme disaster scenarios in analyzing the sheltering demand to avoid an insufficiency of sheltering services in some extreme situations. The analysis of spatial supply is based on the assumption that the evacuees would have a behavioral tendency to go to a nearer shelter when an earthquake happens.

Using the result of the estimation method, the spatial supply $(S S)$ of shelters is mapped in Fig. 7. This figure shows that the high $S S$ areas are mainly distributed in the urban areas (the northern part) of Pudong. Some high SS areas are found in the central and southern areas of Pudong, due to the distribution of nearby green areas and parks (such as Nanhui Taohua Village and Shanghai Binhai Forest Park).

Based on Table 3, the table of evacuation ratio of different land use types against earthquake damage, the evacuation ratios of different land uses under the earthquake scenario of seismic intensity 9 were obtained (Chen et al. 2016, p. 13). We multiplied the daytime and nighttime population estimation results (Fig. 5) with the relative (b)

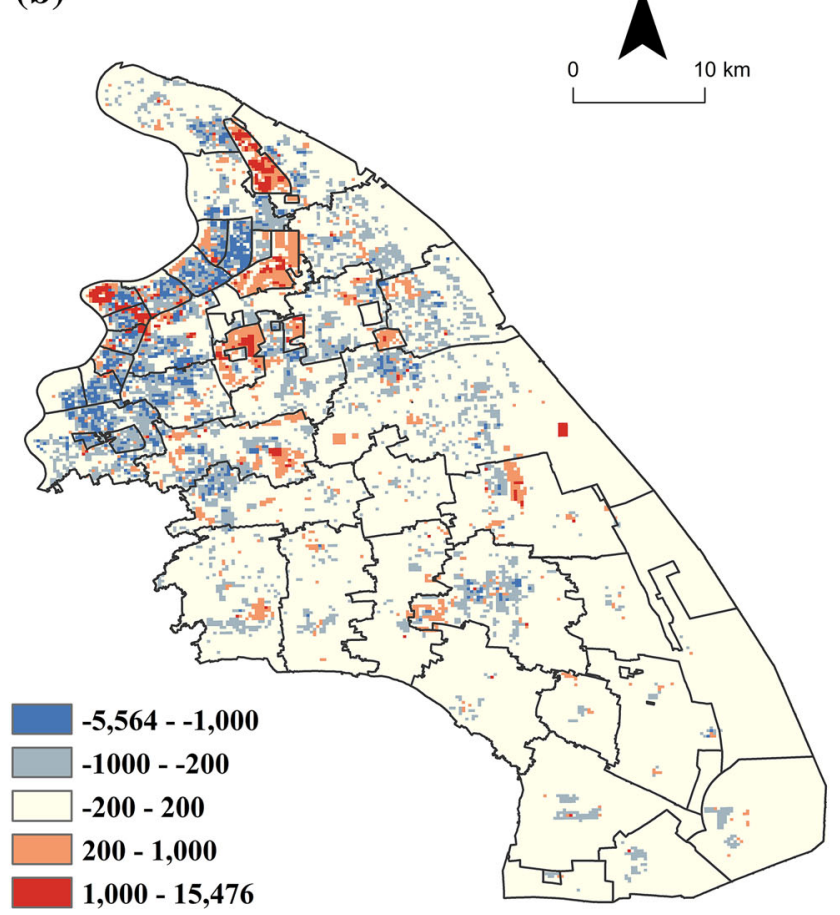

scale (a positive number means there are more people in the daytime than at night, while negative number means there are more people at night than in the daytime)

evacuation ratios of different land uses and generated the predicted evacuation population in the daytime and at night.

Subtracting the SS from the daytime and nighttime predicted the evacuation population separately, the spatial supply-demand analysis results can be mapped (Fig. 8). We used the natural break classification method to classify the supply-demand analysis results into five classes: highly unsatisfied, medium-high unsatisfied, marginally satisfied, medium-high satisfied, and highly satisfied, according to the proportional relation between spatial supply and demand.

In the daytime scenario, Fig. 8a shows that the urban emergency shelters can satisfy the sheltering demand of most regions in Pudong. The highly unsatisfied regions are mainly distributed in the western area of Pudong, including Lujiazui Financial and Trade Zone, Zhangjiang Hi-Tech Park, Heqing Industry Park, and Waigaoqiao Free Trade Zone (Fig. 1), where a large working population gathered.

In the nighttime scenario, Fig. $8 \mathrm{~b}$ shows that the unsatisfied areas are wider distributed than the daytime scenario. The large unsatisfied areas appear in the northwestern and central residential regions of Pudong. The southern part of Pudong can be mostly satisfied by the emergency shelters because fewer people live there and 


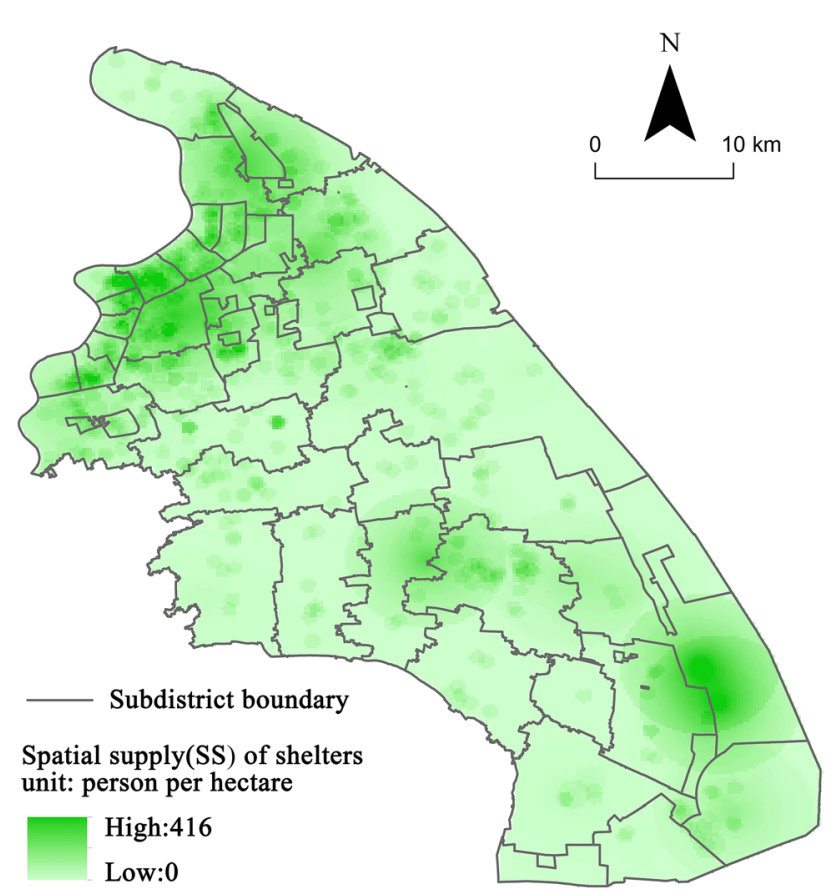

Fig. 7 Spatial supply (SS) of urban emergency shelters in Pudong, China

large parks can be used as emergency shelters for evacuation in a disaster or emergency event.

Figure 9 is the spatial cross-analysis result of the highly unsatisfied areas in daytime and nighttime. The highly unsatisfied and medium-high unsatisfied areas in Fig. 8 are reclassified into one class-unsatisfied areas-and the study area is classified into four classes: (1) unsatisfied areas both in daytime and nighttime; (2) unsatisfied areas only in daytime; (3) unsatisfied areas only in nighttime; and (4) satisfied areas both in daytime and nighttime. Figures 8 and 9 indicate that the spatial distribution of the unsatisfied areas has great differences between the daytime and nighttime scenarios. Most of the unsatisfied areas in nighttime are distributed in residential regions, and the unsatisfied areas in daytime are mainly distributed in commercial areas and industrial parks. Only a small part of Lujiazui and Weifang are unsatisfied areas both in daytime and nighttime.

When an earthquake of intensity 9 happens, even when all potentially available shelters are considered, sheltering supply still cannot satisfy the demand of population evacuation and sheltering both in the daytime and at night, especially in the northern region of Pudong where a large population lives. Because the northern region is a part of the central area of Shanghai, however, there is limited land that can be allocated to build extra shelters. This is the main contradiction between the supply of and demand for emergency shelters in Pudong.

\subsection{Preliminary Location Selection Analysis of Urban Emergency Shelters}

A preliminary location selection analysis of urban emergency shelters based on the supply-demand analysis results was conducted in the study area. Figure 10 shows that the distribution of unsatisfied areas has a strong correlation with time. Therefore, both daytime and nighttime scenarios were taken into consideration in the shelter location selection. We summed up the daytime and nighttime unsatisfied population and generated the integrated unsatisfied population distribution. This distribution was considered the basic population condition in shelter location selection.

Several influencing factors are considered in the location selection analysis. First, an emergency shelter must be located within the functional region of an emergency medical service as well as emergency resource storage and supply facilities. The emergency medical service and resources can be provided by nearby hospitals and resource centers. The distances from these services to a emergency shelter have a remarkable impact on the location selection suitability of the shelter. Second, referring to the Design Standard for Emergency Shelter (DG/TJ 08-2188-2015) and previous studies, gas stations are potentially dangerous sites of explosion. New emergency shelters should avoid locating near gas stations. Third, nearby road condition and accessibility can affect the efficiency of evacuation. Therefore, to evaluate the location selection suitability of shelters, five criteria were selected: (1) distance to hospitals (DH); (2) distance to gas stations (DGS); (3) distance to resource centers (DRC); (4) distance to roads (DR); and (5) road density (RD). The distances of the first four criteria were all defined as Euclidean distance. The road density of a grid was calculated by the total road length within a buffer zone of the grid divided by the area of the buffer zone. We classified the suitability of these five criteria into three classes-suitable, marginally suitable, and unsuitable. The threshold values of the criteria are shown in Table 4. Several local experts were involved in discussing and determining the pairwise comparison matrix of the five criteria (Table 5) by evaluating the relative importance between each two criteria. Based on the matrix, the AHP method was applied to calculate the weights of the five criteria (Fig. 10). Different criteria layers were overlaid by the weighted overlaying method and this generated the shelter location selection suitability of the study area (Fig. 11).

By applying the focal statistics for the integrated unsatisfied population in the suitable areas of Fig. 11f, the final location selection results were generated (Fig. 12). Figure 12 shows that there are 45 new shelters that have been spatially located. In Fig. 12, some sample regions 
(a) Daytime

(b) Nighttime

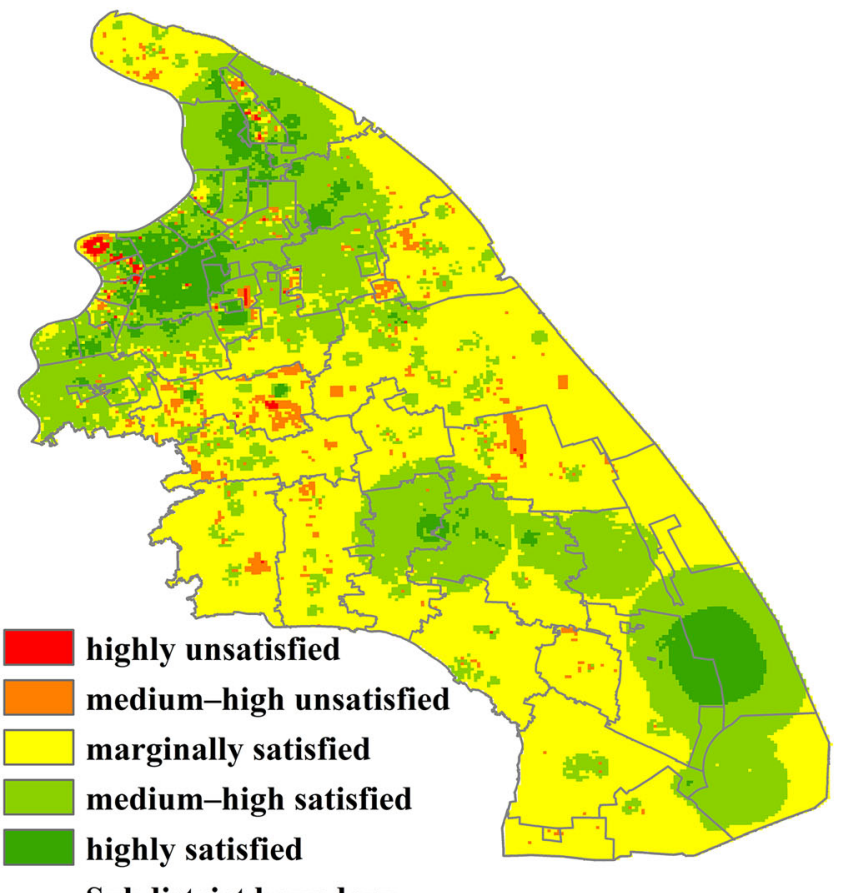

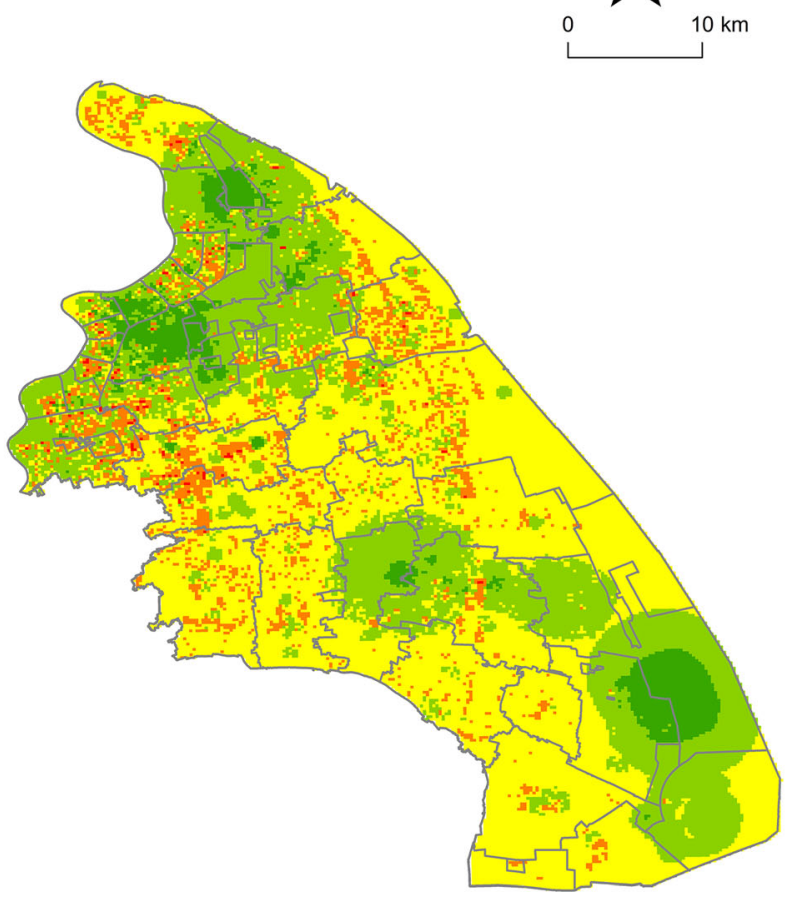

Fig. 8 Daytime and nighttime supply-demand analysis results of urban emergency shelters in Pudong, China

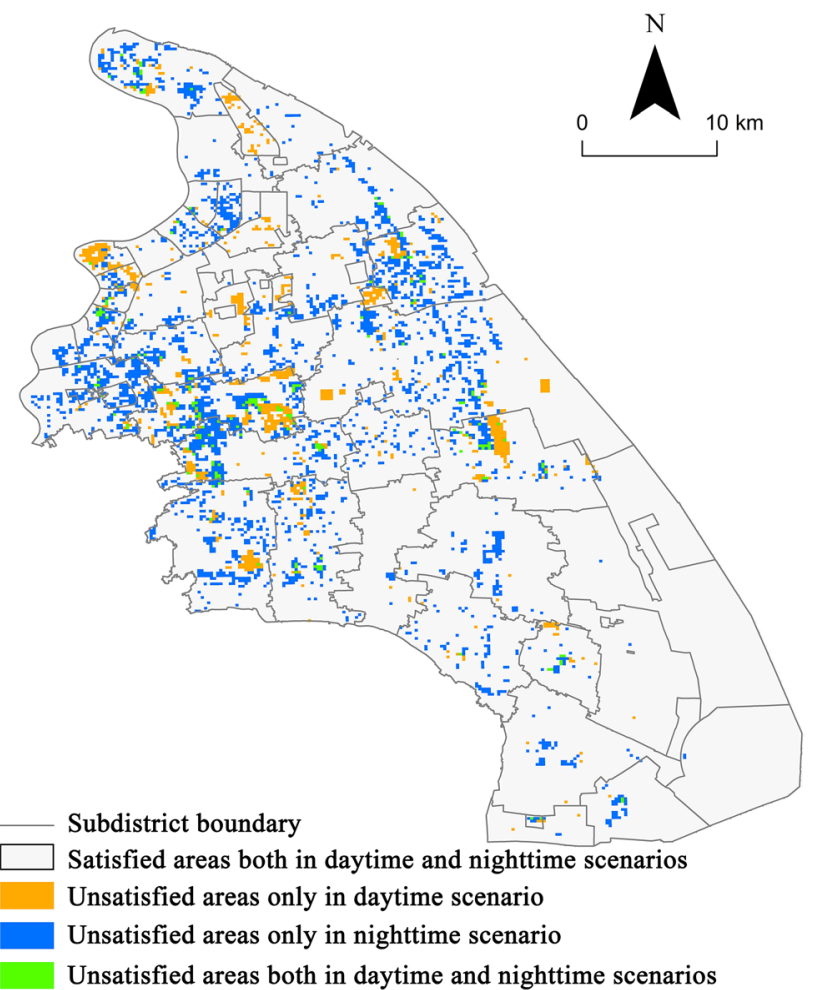

Fig. 9 Cross-analysis of unsatisfied areas in daytime and nighttime in Pudong, China have been enlarged, such as Lujiazui, Zhangjiang Hi-Tech Park, Industrial Park near Kangxin Highway, and Industrial Park near Fengfeng Highway. In these regions, new located shelters are all in the intersection areas of unsatisfied areas only in daytime and unsatisfied areas only in nighttime, that is, the location selection results consider the difference of population distribution in the daytime and at night. If new urban emergency shelters are built in these locations, it can enhance the satisfaction of emergency shelters for evacuating population both in daytime and nighttime.

\subsection{Discussion}

Based on the results of the supply-demand analysis of shelters, it is clear that the spatiotemporal imbalance between spatial supply and demand of urban emergency shelters in Pudong is serious and the problem is related to the limitation and scarcity of land resources in the process of urbanization. For the suburban area and central urban area of Pudong, the solutions discussed differ.

In the suburban areas, most regions can be satisfied by the proposed shelters. At nighttime, the regions in the urban-rural fringe, such as Sanlin, Chuansha, and Heqing, are unsatisfied mainly due to the high resident density. In the daytime, some industrial areas are unsatisfied due to the 
(a)

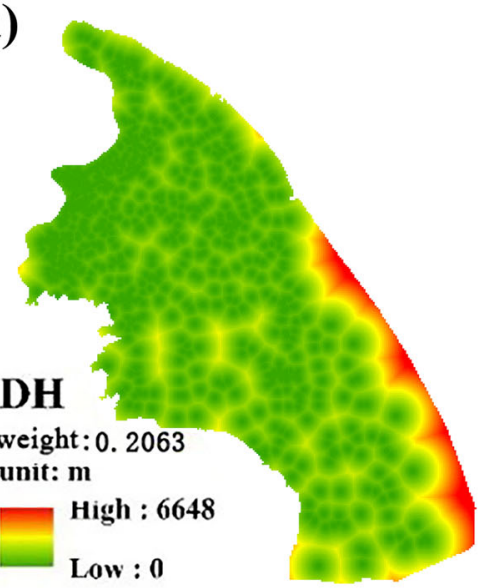

(d)

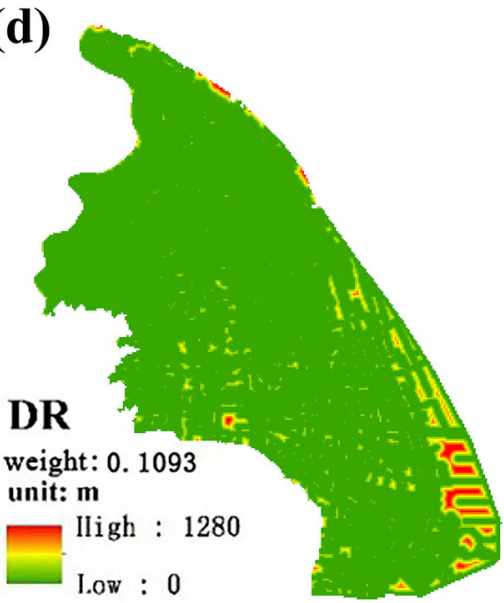

(b)

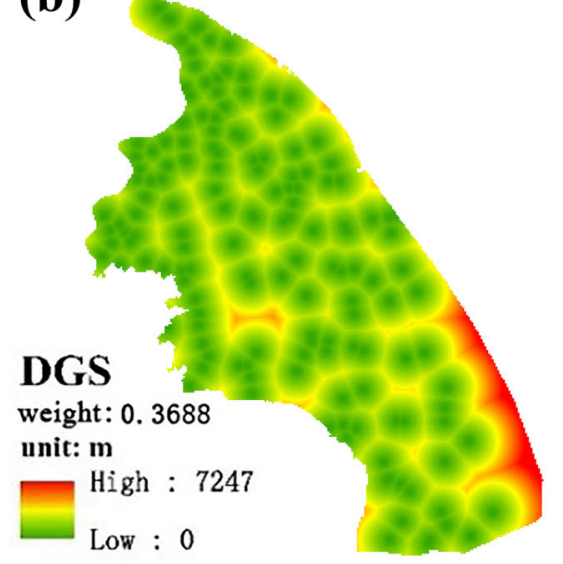

(e)

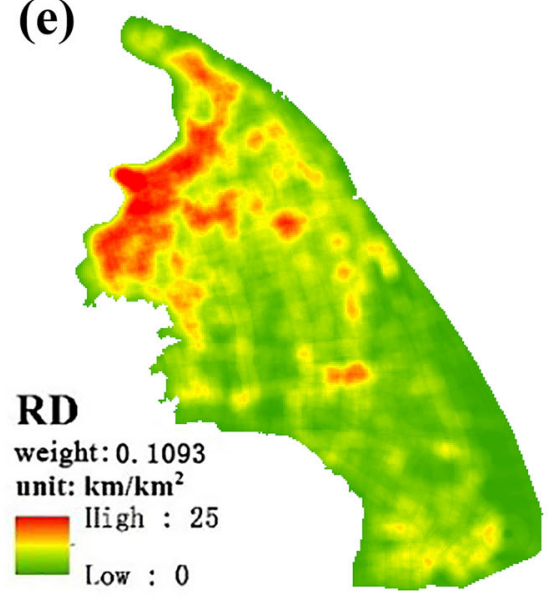

(c)

DRC

weight: 0.2063

unit: $\mathbf{m}$

High : 6280
Low : 0

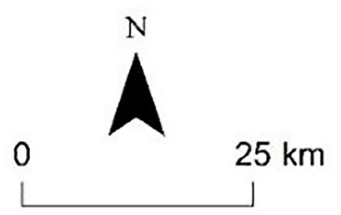

DH : distance to hospitals

DGS : distance to gas stations

DRC: distance to resource centers

$\mathrm{DR}$ : distance to roads

$\mathrm{RD}$ : road density

Fig. 10 The five criteria layers for Pudong, China

Table 4 Suitability classification of five criteria in location selection suitability evaluation

\begin{tabular}{llllll}
\hline Criteria & DH & DGS & DRC & DR & RD \\
\hline Unsuitable & $>1000 \mathrm{~m}$ & $<1000 \mathrm{~m}$ & $>500 \mathrm{~m}$ & $>200 \mathrm{~m}$ & $<3 \mathrm{~km} / \mathrm{km}^{2}$ \\
Marginally suitable & $800-1000 \mathrm{~m}$ & $1000-1300 \mathrm{~m}$ & $400-500 \mathrm{~m}$ & $150-200 \mathrm{~m}$ & $3-4 \mathrm{~km} / \mathrm{km}^{2}$ \\
Suitable & $\leq 800 \mathrm{~m}$ & $\geq 1300 \mathrm{~m}$ & $\leq 400 \mathrm{~m}$ & $\leq 150 \mathrm{~m}$ & $\geq 4 \mathrm{~km} / \mathrm{km}^{2}$ \\
\hline
\end{tabular}

high working population density. However, considering that there are large vacant areas in the suburban area that can be converted to emergency shelters, the location-allocation schemes for emergency shelters are feasible and flexible.

In the central urban area, many places are unsatisfied by sheltering services because a large population lives in this area. At night, most residential communities in the northern part, such as Puxing, Weifang, Huamu, and Shanggang, are unsatisfied mainly because of the high resident density. In the daytime, Lujiazui, Zhangjiang, and Waigaoqiao are unsatisfied due to their big working population. In the
Table 5 Pairwise comparison matrix of the five criteria

\begin{tabular}{llllll}
\hline & DH & DGS & DRC & DR & RD \\
\hline DH & 1 & $1 / 2$ & 1 & 2 & 2 \\
DGS & 2 & 1 & 2 & 3 & 3 \\
DRC & 1 & $1 / 2$ & 1 & 2 & 2 \\
DR & $1 / 2$ & $1 / 3$ & $1 / 2$ & 1 & 1 \\
RD & $1 / 2$ & $1 / 3$ & $1 / 2$ & 1 & 1 \\
\hline
\end{tabular}

Note: $\mathrm{DH}=$ distance to hospitals; DGS = distance to gas stations; $\mathrm{DRC}=$ distance to resource centers; $\mathrm{DR}=$ distance to roads; and $\mathrm{RD}=$ road density 

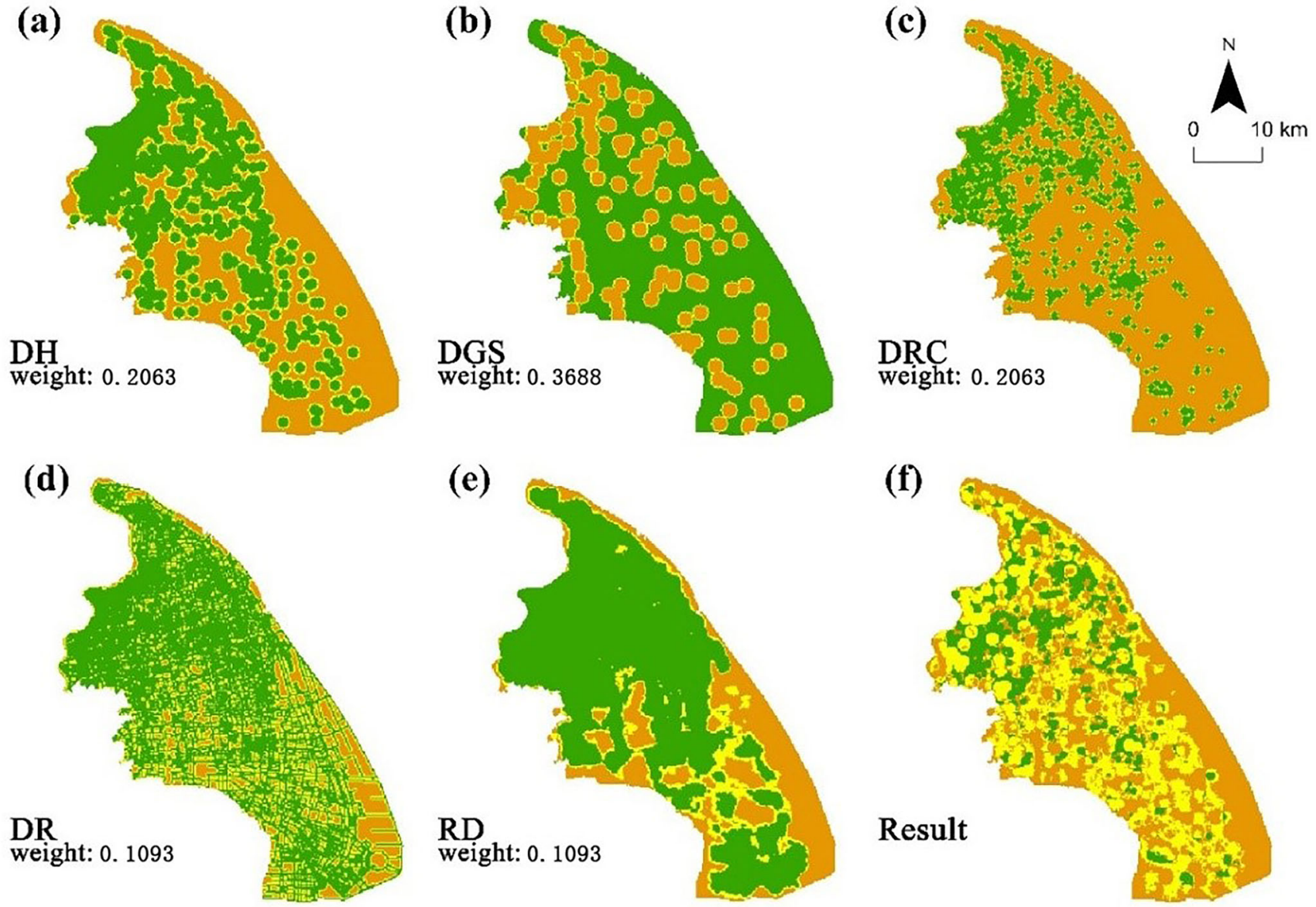

(f)

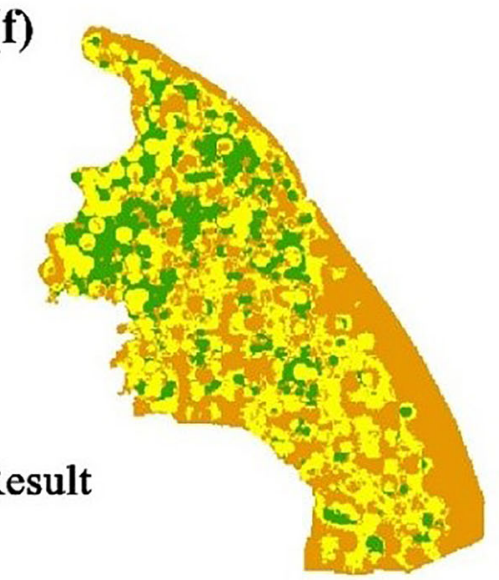

\section{Suitable Marginally suitable}

\section{Unsuitable}

Fig. 11 Shelter location selection suitability of Pudong, China

central urban area, there is little vacant land that can be allocated to build new shelters due to the existing high land utilization rate. Only the green spaces, squares, stadiums, and schools can be transformed into emergency shelters. Therefore, local decision makers have to expand the existing urban emergency shelters to improve their capacity. Otherwise, it is necessary to allocate new emergency shelters in the highly unsatisfied regions in the central urban area with high cost. Whether expanding the existing urban shelters or allocating new emergency shelters, the daytime and nighttime supply-demand analysis of the urban emergency shelters in this study can provide more reasonable decision support than traditional supply-demand analytic methods.

The results of the preliminary location selection of urban emergency shelters show the advantages of the supplydemand analysis used in this study. We suggest that a more detailed location selection work, which considers the supply-demand difference of daytime and nighttime populations, should be undertaken soon for the Pudong New Area.
This effort would better help evacuate population reasonably and efficiently when a disaster occurs.

\section{Conclusion}

In this study, we proposed a supply-demand analysis method of urban emergency shelters on the basis of daytime and nighttime population estimation at a fine scale. The daytime and nighttime population distributions were estimated by a series of equations based on the land use data, local population census and economic census data, high-precision building data, and Tencent User Density (TUD) big data acquired from the Internet. According to the design standards for emergency shelters in Shanghai, we selected all the potentially available lands as shelters and classified these shelters into different classes. We used a spatial probability density estimation method to calculate the spatial supply of each location acquired from shelters. Evacuation population (demand of sheltering) was 


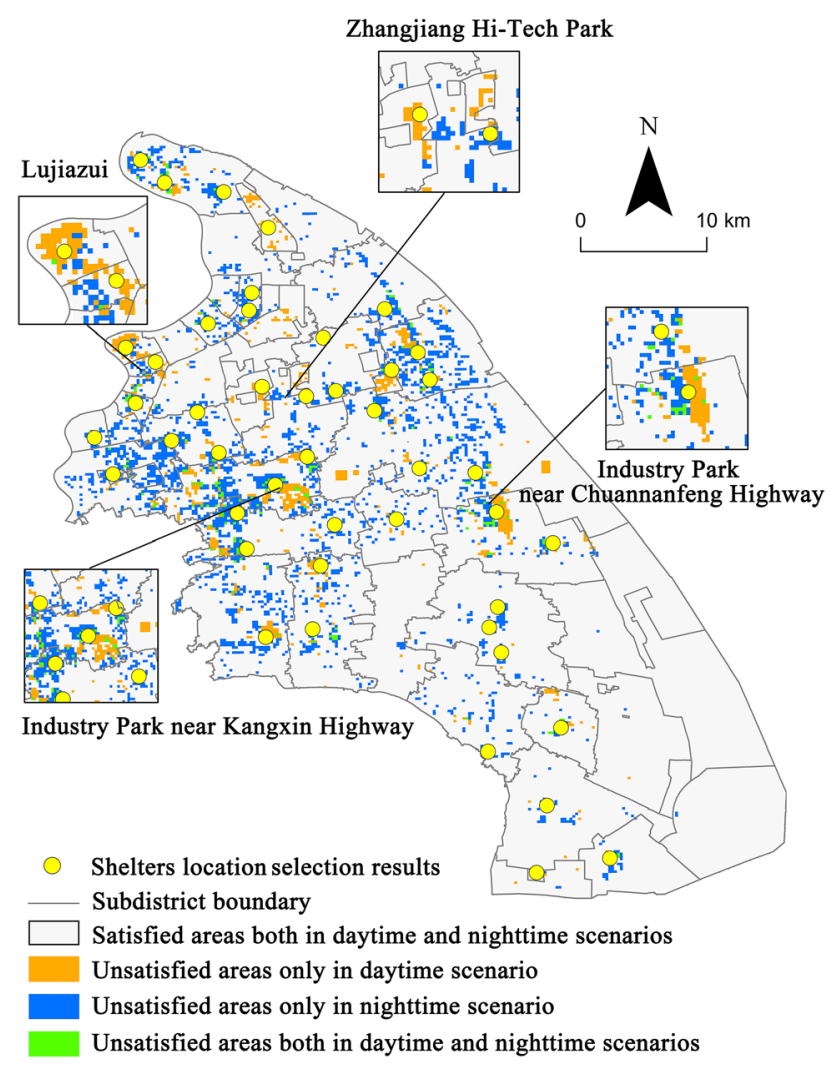

Fig. 12 Final location selection results for Pudong, China

predicted under an earthquake scenario. By calculating the difference between the spatial supply and the sheltering demand, supply-demand analysis was conducted to assess the satisfaction of sheltering service in daytime and nighttime, respectively. The advantages of this method lies in the fact that (1) the improved supply-demand analysis can map the spatial satisfaction of sheltering service from a microcosmic perspective on the basis of high precision population estimation; and (2) the supply-demand analysis can be conducted separately for the daytime and nighttime need for sheltering in support of more reasonable decision making for location-allocation and expansion of urban emergency shelters.

A case study in Pudong New Area, Shanghai, China was conducted to prove the feasibility and effectiveness of the proposed method. We also conducted a preliminary location selection analysis of shelters based on the supplydemand analysis results. The location selection results show the practicability of the analysis results. The supplydemand analysis results can evaluate the existing and potentially available urban emergency shelters and help to make better the urban planning work of new emergency shelters.

The limitations of this study are as follows: (1) Due to the data limitation, we used the volumetric method for population estimation. However, some urban apartments may have been bought for investment purposes and are not occupied. In the future we will conduct field surveys and use actual population data to rectify the population estimation results; and (2) We only considered the earthquake scenario for the supply-demand analysis. In future work we would improve the supply-demand analysis of emergency shelters, which takes different disaster scenarios into consideration.

Acknowledgements The study was funded by the National Natural Science Foundation of China (Grant Nos. 41201548 and 5161101688), and National Social Science Foundation of China (Grant No. 18ZDA105).

Open Access This article is licensed under a Creative Commons Attribution 4.0 International License, which permits use, sharing, adaptation, distribution and reproduction in any medium or format, as long as you give appropriate credit to the original author(s) and the source, provide a link to the Creative Commons licence, and indicate if changes were made. The images or other third party material in this article are included in the article's Creative Commons licence, unless indicated otherwise in a credit line to the material. If material is not included in the article's Creative Commons licence and your intended use is not permitted by statutory regulation or exceeds the permitted use, you will need to obtain permission directly from the copyright holder. To view a copy of this licence, visit http://creativecommons. org/licenses/by/4.0/.

\section{References}

Alçada-Almeida, L., L. Tralhão, L. Santos, and J. CoutinhoRodrigues. 2009. A multiobjective approach to locate emergency shelters and identify evacuation routes in urban areas. Geographical Analysis 41(1): 9-29.

Aubrecht, C., S. Freire, C. Neuhold, A. Curtis, and K. Steinnocher. 2012. Introducing a temporal component in spatial vulnerability analysis. Disaster Advances 5(2): 48-53.

Blaikie, P., T. Cannon, I. Davis, and B. Wisner. 2004. At risk: Natural hazards, people's vulnerability and disasters. London and New York: Routledge.

Brockmann, D., L. Hufnagel, and T. Geisel. 2006. The scaling laws of human travel. Nature 439(7075): 462-465.

Cetinkaya, C., E. Özceylan, M. Erbaş, and M. Kabak. 2016. GISbased fuzzy MCDA approach for siting refugee camp: A case study for southeastern Turkey. International Journal of Disaster Risk Reduction 18: 218-231.

Chen, Y., X. Liu, X. Li, X. Liu, Y. Yao, G. Hu, X. Xu, and F. Pei. 2017. Delineating urban functional areas with building-level social media data: A dynamic time warping (DTW) distance based k-medoids method. Landscape and Urban Planning 160: $48-60$.

Chen, Z, X. Chen, Q. Li, and J. Chen. 2013. The temporal hierarchy of shelters: A hierarchical location model for earthquake-shelter planning. International Journal of Geographical Information Science 27(8): 1612-1630.

Chen, Y., X. Liu, W. Gao, R. Yu Wang, Y. Li, and W. Tu. 2018a. Emerging social media data on measuring urban park use. Urban Forestry \& Urban Greening 31: 130-141.

Chen, Z, B. Qiao, and J. Zhang. 2018b. Identification and spatial interaction of urban functional regions in Beijing based on the 
characteristics of residents' traveling. Journal of Geo-Information Science 20(3): 291-301 (in Chinese).

Chen, Z, J. Zhou, J. Wang, L. Zou, and Y. Xie. 2016. A simple way to predict the evacuation population in the emergency shelter planning: Exemplified by earthquake disasters. City Planning Review 40(9): 105-112 (in Chinese).

Cheng, H., and X. Yang. 2011. Theory model for earthquake emergency shelter choice based on the shortest overall evacuation time. In ICTIS 2011: Multimodal approach to sustained transportation system development: Information, technology, implementation, ed. X. Yan, P. Yi, C. Wu, and M. Zhong, 1268-1274. Reston, VA: American Society of Civil Engineers.

Cheng, H., and X. Yang. 2012. A comprehensive evaluation model for earthquake emergency shelter. In Sustainable transportation systems: Plan, design, build, manage, and maintain, ed. Y. Bai, W.V. Ping, L.D. Shen, and X. Chen, 412-422. Reston, VA: American Society of Civil Engineers.

China, People's Republic of. Ministry of Land and Resources. 2002. National land classification. Beijing: Ministry of Land and Resources of the People's Republic of China. http://www. 360doc.com/content/12/0202/12/8533258_183610719.shtml. Accessed 3 Jun 2020 (in Chinese).

China, People's Republic of. National Bureau of Statistics. 2011a. Tabulation on the 2010 population census of the People's Republic of China. Beijing: China Statistics Press (in Chinese).

China, People's Republic of. Pudong New Area Bureau of Statistics (PNABS). 2011b. Shanghai Pudong New Area statistical yearbook. Beijing: China Statistics Press (in Chinese).

China, People's Republic of. Shanghai Municipality. 2015a. Bulletins of the third economic census (2013) in Pudong New Area, Shanghai. Shanghai: Shanghai Municipal Bureau of Statistics (in Chinese).

China, People's Republic of. China Earthquake Administration. 2015b. Seismic ground motion parameter zonation map of China (GB 18306-2015). Beijing: Standards Press of China (in Chinese)

China, People's Republic of. Shanghai Municipal Administration Committee of Housing and Urban-Rural Development. 2016a. Design standard for emergency shelter (DG/TJ 08-2188-2015) Section 3.1. Shanghai: Tongji University Press. http://ebook. chinabuilding.com.cn/zbooklib/book/detail/show?SiteID= 1\&bookID=62291. Accessed 3 Jun 2020 (in Chinese).

China, People's Republic of. Shanghai Municipal Bureau of Statistics. 2016b. Shanghai Pudong New Area statistical yearbook 2016. Shanghai: China Statistics Press (in Chinese).

China, People's Republic of. Shanghai Municipal Bureau of Statistics. 2017. Shanghai Pudong New Area statistical yearbook 2017. Shanghai: China Statistics Press (in Chinese).

Choi, J., I. Kang, and S. King. 2012. Study on the selection of the tsunami shelter using AHP and GIS analysis. Journal of the Korean Society of Surveying, Geodesy, Photogrammetry and Cartography 30(6): 503-509.

Choi, S.M., C.K. Park, and J.Y. Park. 2014. A spatio-temporal analysis of population and employment growth for Southern California. The Annals of Regional Science 52(1): 19-40.

Chu, J., and Y. Su. 2012. The application of TOPSIS method in selecting fixed seismic shelter for evacuation in cities. Systems Engineering Procedia 3: 391-397.

Dai, S., L. He, and Y. Su. 2013. Problem analysis of planning and construction on emergency disaster mitigation shelter in Shanghai. Shanghai Urban Planning Review 4: 40-43 (in Chinese).

Dilley, M., R.S. Chen, U. Deichmann, A.L. Lerner-Lam, and M. Arnold. 2005. Natural disaster hotspots: A global risk analysis. Washington, DC: The World Bank.
Ding, J., H. Yang, H. Zhang, and P. Lu. 2003. Defining and interpreting the age pattern of migrating population in small areas. Population Research 27(1): 20-27 (in Chinese).

Dou, K., Q. Zhan, and S. Li. 2012. GIS-based responsibility area subdivision for metropolitan emergency shelters-Case study of Wuchang district, Wuhan city. In Proceedings of 6th International Association for China Planning (IACP) Conference "China's Urbanization in Transition: Challenges and Opportunities," 17-19 June 2012, Wuhan, China.

ESRI (Environmental Systems Research Institute, Inc.). 2017. ArcGIS for Desktop help: Focal statistics. https://desktop. arcgis.com/en/arcmap/10.3/tools/spatial-analyst-toolbox/focalstatistics.htm. Accessed 23 May 2020.

Fan, L., Y. Tong, and R. Li. 2011. Notice of retraction evaluation of urban community shelters, Jiaozuo City, China. In 2011 2nd International Conference on Artificial Intelligence, Management Science, and Electronic Commerce (AIMSEC), 8-10 August 2011, Zhengzhou, China.

Freire, S., C. Aubrecht, and S. Wegscheider. 2013. Advancing tsunami risk assessment by improving spatio-temporal population exposure and evacuation modeling. Natural Hazards 68(3): 1311-1324.

Gonzalez, M.C., C.A. Hidalgo, and A.-L. Barabasi. 2008. Understanding individual human mobility patterns. Nature 453(7196): 779-782.

Jiang, B., J. Yin, and S. Zhao. 2009. Characterizing the human mobility pattern in a large street network. Physical Review E 80(2): Article 021136.

Jin, M. 2013. Study on the emergency shelter plan in Shanghai: A case study of Xuhui District. Shanghai Urban Planning Review 4: 63-68 (in Chinese).

Johnson, R. 2000. GIS technology for disasters and emergency management. An ESRI white paper. https://www.esri.com/ library/whitepapers/pdfs/disastermgmt.pdf. Accessed $16 \mathrm{Feb}$ 2019.

Kongsomsaksakul, S., C. Yang, and A. Chen. 2005. Shelter locationallocation model for flood evacuation planning. Journal of the Eastern Asia Society for Transportation Studies 6: 4237-4252.

Kulshrestha, A., D. Wu, Y. Lou, and Y. Yin. 2011. Robust shelter locations for evacuation planning with demand uncertainty. Journal of Transportation Safety \& Security 3 (4): 272-288.

Li, A.C., L. Nozick, N. Xu, and R. Davidson. 2012. Shelter location and transportation planning under hurricane conditions. Transportation Research Part E: Logistics and Transportation Review 48(4): 715-729.

Lloyd, C.D., and B.F. Nejad. 2014. Surface models and the spatial structure of population variables: Exploring smoothing effects using Northern Ireland grid square data. Computers, Environment and Urban Systems 48: 64-72.

Long, Y., and X.J. Liu. 2013. Automated identification and characterization of parcels (AICP) with OpenStreetMap and Points of Interest. Environment and Planning B: Planning and Design 43(2): $1-26$.

Lwin, K.K., and Y. Murayama. 2011. Estimation of building population from LIDAR derived digital volume model. In Spatial analysis and modeling in geographical transformation process, ed. Y. Murayama, and R.B. Thapa, 87-98. The Netherlands: Springer.

Niu, N., X. Liu, H. Jin, X. Ye, Y. Liu, X. Li, Y. Chen, and S. Li. 2017. Integrating multi-source big data to infer building functions. International Journal of Geographical Information Science 31(9): 1871-1890.

Pan, A. 2010. The applications of maximal covering model in typhoon emergency shelter location problem. In The Proceedings of 2010 IEEE International Conference on Industrial 
Engineering and Engineering Management, Macau, December 7-10, 2010, 1727-1731. Piscataway: IEEE Press.

Qi, W., S. Liu, X. Gao, and M. Zhao. 2015. Modeling the spatial distribution of urban population during the daytime and at night based on land use: A case study in Beijing, China. Journal of Geographical Sciences 25(6): 756-768.

Qiu, F., H. Sridharan, and Y. Chun. 2010. Spatial autoregressive model for population estimation at the census block level using LIDAR-derived building volume information. Cartography and Geographic Information Science 37(3): 239-257.

Sherali, H.D., T.B. Carter, and A.G. Hobeika. 1991. A locationallocation model and algorithm for evacuation planning under hurricane/flood conditions. Transportation Research Part B: Methodological 25(6): 439-452.

Sherratt, G.G. 1960. A model for general urban growth. In Management sciences: Models and techniques. Proceedings of the sixth international meeting of the Institute of Management Sciences at the Conservatoire National des Arts \& Métiers, Paris, September 7-11, 1959, ed. C.W. Churchman, and M. Verhulst, Vol. 2, 147-159. New York: Pergamon Press.

Shiode, N., M. Morita, S. Shiode, and K.-I. Okunuki. 2014. Urban and rural geographies of aging: A local spatial correlation analysis of aging population measures. Urban Geography 35(4): 608-628.

Smeed, R.J. 1964. The traffic problem in towns: A review of possible long term solutions. Town Planning Review 35(2): 133-158.

Song, C., T. Koren, P. Wang, and A.L. Barabási. 2010. Modelling the scaling properties of human mobility. Nature Physics 6(10): 818-823.

Song, X., Y. Wang, K. Zhang, Y. Yang, C. Sun, and J. Wang. 2017. Measurement of jobs-housing separation based on commuting distance. Urban Planning Forum 6: 25-32 (in Chinese).

Tai, C., Y. Lee, and C. Lin. 2010. Earthquake disaster prevention area planning considering residents' demand. In Proceedings of the 2nd International Conference on Advanced Computer Control, Shenyang, China, 27-29 March 2010, 381-385. Piscataway: IEEE Press.

Tang, J., and X. Zhao. 2005. A comparative study on the population prediction models in land use planning. China Land Science 19(2): 14-20 (in Chinese).

Tong, Z., J. Zhang, and X. Liu. 2012. GIS-based design of urban emergency shelter in Songbei Harbin. In Recent advances in computer science and information engineering, ed. Z. Qian, L. Cao, W. Su, T. Wang, and H.. Yang, 617-622. New York and London: Springer.

Trivedi, A., and A. Singh. 2017. A hybrid multi-objective decision model for emergency shelter location-relocation projects using fuzzy analytic hierarchy process and goal programming approach. International Journal of Project Management 35(5): 827-840.

Tsai, C., C. Chen, W. Chiang, and M. Lin. 2008. Application of geographic information system to the allocation of disaster shelters via fuzzy models. Engineering Computations 25(1): 86-100.

UN (United Nations). 2014. World urbanization prospects: The 2014 revision-highlights. New York: United Nations.

Xu, W., Y. Ma, X. Zhao, Y. Li, L. Qin, and J. Du. 2017. A comparison of scenario-based hybrid bilevel and multi-objective location-allocation models for earthquake emergency shelters: a case study in the central area of Beijing, China. International Journal of Geographical Information Science 32(2): 236-256.

Xu, W., X. Zhao, Y. Ma, Y. Li, L. Qin, Y. Wang, and J. Du. 2018. A multi-objective optimization based method for evaluating earthquake shelter location-allocation. Geomatics, Natural Hazards and Risk 9(1): 662-677.

Yao, Y., X. Liu, X. Li, J. Zhang, Z. Liang, K. Mai, and Y. Zhang. 2017. Mapping fine-scale population distributions at the building level by integrating multisource geospatial big data. International Journal of Geographical Information Science 31(6): $1220-1244$.

Ye, M., J. Wang, Y. Liu, and S. Xu. 2008. Study on refuge accessibility of park in inner-city of Shanghai based on GIS technique. Geography and Geo-Information Science 24(2): 96-103 (in Chinese).

Yin, Z., and S. Yang. 2004. Earthquake disaster loss research and criteria of resistance. Beijing: Seismological Press (in Chinese).

Yu, B., M. Tang, Q. Wu, C. Yang, S. Deng, K. Shi, C. Peng, J. Wu, and Z. Chen. 2018. Urban built-up area extraction from logtransformed npp-viirs nighttime light composite data. IEEE Geoscience and Remote Sensing Letters 15(8): 1279-1283.

$\mathrm{Yu}$, J., and J. Wen. 2016. Multi-criteria satisfaction assessment of the spatial distribution of urban emergency shelters based on highprecision population estimation. International Journal of Disaster Risk Science 7(4): 413-429.

Zhao, L., H. Li, Y. Sun, R. Huang, Q. Hu, J. Wang, and F. Gao. 2017. Planning emergency shelters for urban disaster resilience: An integrated location-allocation modeling approach. Sustainability 9(11): Article 2098.

Zhao, L., M. Ting, J. Wang, and K. Wang, 2013. Discussion on the layout and construction of urban emergency shelter-Taking Shanghai as an example. Industrial Safety \& Environmental Protection 39(11): 61-65 (in Chinese).

Zhu, X., Z. Tong, X. Liu, X. Li, P. Lin, and T. Wang. 2018. An improved two-step floating catchment area method for evaluating spatial accessibility to urban emergency shelters. Sustainability 10(7): Article 2180. 